Supplement of Atmos. Chem. Phys., 19, 5589-5604, 2019

https://doi.org/10.5194/acp-19-5589-2019-supplement

(c) Author(s) 2019. This work is distributed under

the Creative Commons Attribution 4.0 License.

(c) (1)

Supplement of

\title{
Characterization of aerosol growth events over Ellesmere Island during the summers of 2015 and 2016
}

Samantha Tremblay et al.

Correspondence to: Patrick L. Hayes (patrick.hayes@umontreal.ca) and Rachel Chang (rachel.chang@ dal.ca)

The copyright of individual parts of the supplement might differ from the CC BY 4.0 License. 


\section{Supplementary RidgeLab aerosol inlet description}

At the PEARL RidgeLab, the instruments sampled year-round through a common aerosol inlet, made of $6 \mathrm{~m}$ of stainless steel tubing with a $25.4 \mathrm{~mm}$ outer diameter (OD) and an inner diameter (ID) of $22 \mathrm{~mm}$, sampling $2 \mathrm{~m}$ above the roof of the laboratory with a total flow rate of $11 \mathrm{~L} / \mathrm{min}$, as previously described by Kuhn et al. (2010). The SMPS flow passed first through $0.5 \mathrm{~m}$ of $25.4 \mathrm{~mm}$ OD and $22 \mathrm{~mm}$ ID stainless steel tubing connected to the common aerosol inlet; this flow then entered a $9.53 \mathrm{~mm}$ OD stainless steel tube with a length of $0.45 \mathrm{~m}$ and finally passed through a $6.35 \mathrm{~mm}$ OD and $4.72 \mathrm{~mm}$ ID copper tube that was $1.05 \mathrm{~m}$ long. For the OPC, the flow passed from the common aerosol inlet into a $12.7 \mathrm{~mm}$ OD copper tube with an ID of $9.40 \mathrm{~mm}$ and a length of $0.8 \mathrm{~m}$, and then into a $6.35 \mathrm{~mm}$ OD copper tube with an ID of 4.72 $\mathrm{mm}$ and a length of $0.58 \mathrm{~m}$, which was connected to the OPC by $6.35 \mathrm{~mm}$ OD conductive rubber tubing with an ID of 3.18 $\mathrm{mm}$ and a length of $0.04 \mathrm{~m}$. Particle transmission efficiency to the SMPS has been calculated and the resulting transmission

curve is shown in Figure S1 (von der Weiden et al. 2009). From the common aerosol inlet, the AMS flow passed first through $0.5 \mathrm{~m}$ of $25.4 \mathrm{~mm}$ OD and $22 \mathrm{~mm}$ ID stainless steel tubing and then through a $9.53 \mathrm{~mm}$ OD stainless steel tube with a length of $0.45 \mathrm{~m}$ before entering the AMS.

\section{References}

Kuhn, T., Damoah, R., Bacak, A., and Sloan, J. J.: Characterising aerosol transport into the Canadian High Arctic using aerosol mass spectrometry and Lagrangian modelling, Atmospheric Chemistry and Physics, 10, 10489-10502, 2010.

von der Weiden, S. L., Drewnick, F., and Borrmann, S.: Particle Loss Calculator - a new software tool for the assessment of the performance of aerosol inlet systems, Atmospheric Measurement Techniques, 2, 479-494, 2009. 
Table S1. List of all growth events observed near Eureka during the summers of 2015 and 2016.

Event

Number

GE 1

GE 3

GE 6

GE 9

GE 10

GE 15

GE 27

GE 28

GE 30

GE 32

GE 33

GE 34

GE 37

GE 38

GE 39

GE 43

GE 45

GE 46

GE 47

GE 48

GE 49

GE 51

GE 53

GE 54

GE 55

GE 56

GE 58

GE 59
Start

Date and Time (UTC)

2015-07-27 18:00

2015-07-29 05:00

2015-08-02 04:00

2015-08-07 03:00

2015-08-07 21:00

2015-08-18 12:00

2016-06-15 00:00

2016-06-17 00:00

2016-06-25 20:00

2016-07-05 01:00

2016-07-08 07:00

2016-07-09 20:00

2016-07-20 18:00

2016-07-21 19:00

2016-07-27 02:00

2016-08-03 18:00

2016-08-05 03:00

2016-08-05 21:00

2016-08-13 19:00

2016-08-17 23:00

2016-08-20 23:00

2016-08-23 19:00

2016-08-26 19:00

2016-09-04 01:00

2016-09-05 09:00

2016-09-05 15:00

2016-09-10 12:00

2016-09-19 00:00
End

Average temp. change

from 10 to $\left.600 \mathrm{~m} \mathrm{(}{ }^{\circ} \mathrm{C}\right)$
2015-07-28 03:00

2015-07-30 11:00

2015-08-03 05:00

2015-08-08 05:00

2015-08-09 02:00

2015-08-19 04:00

2016-06-17 18:00

2016-06-18 13:00

2016-06-27 14:00

2016-07-08 09:00

2016-07-09 01:00

2016-07-13 18:00

2016-07-22 03:00

2016-07-25 17:00

2016-07-27 17:00

2016-08-04 14:00

2016-08-05 23:00

2016-08-06 17:00

2016-08-17 12:00

2016-08-19 20:00

2016-08-22 15:00

2016-08-25 15:00

2016-08-27 20:00

2016-09-05 09:00

2016-09-06 01:00

2016-09-08 01:00

2016-09-12 16:00

2016-09-20 06:00
2.00

1.10

0.20

0.00

1.23

1.28

1.20

2.25

1.30

2.91

0.00

4.89

1.80

5.77

0.47

0.07

0.00

0.00

0.46

0.00

0.00

0.18

2.27

1.45

4.30

0.56

1.28

0.15 
Table S2. List of selected periods of low and high particle concentrations observed near Eureka during the summers of 2015 and 2016 . The periods of high concentrations do not exhibit particle growth and are therefore distinct from the growth events. The SMPS measurements for the periods of low and high concentrations are shown in Figure S5 and S6, respectively.

\begin{tabular}{crlrl}
\hline \multirow{2}{*}{$\begin{array}{c}\text { Non-Event } \\
\text { (NE) }\end{array}$} & \multicolumn{3}{c}{ Time period (UTC) } & $\begin{array}{c}\text { Average temp. change } \\
\text { from 10 to 600 m ( }\end{array}$ \\
\cline { 2 - 5 } $\mathbf{C}$ C)
\end{tabular}




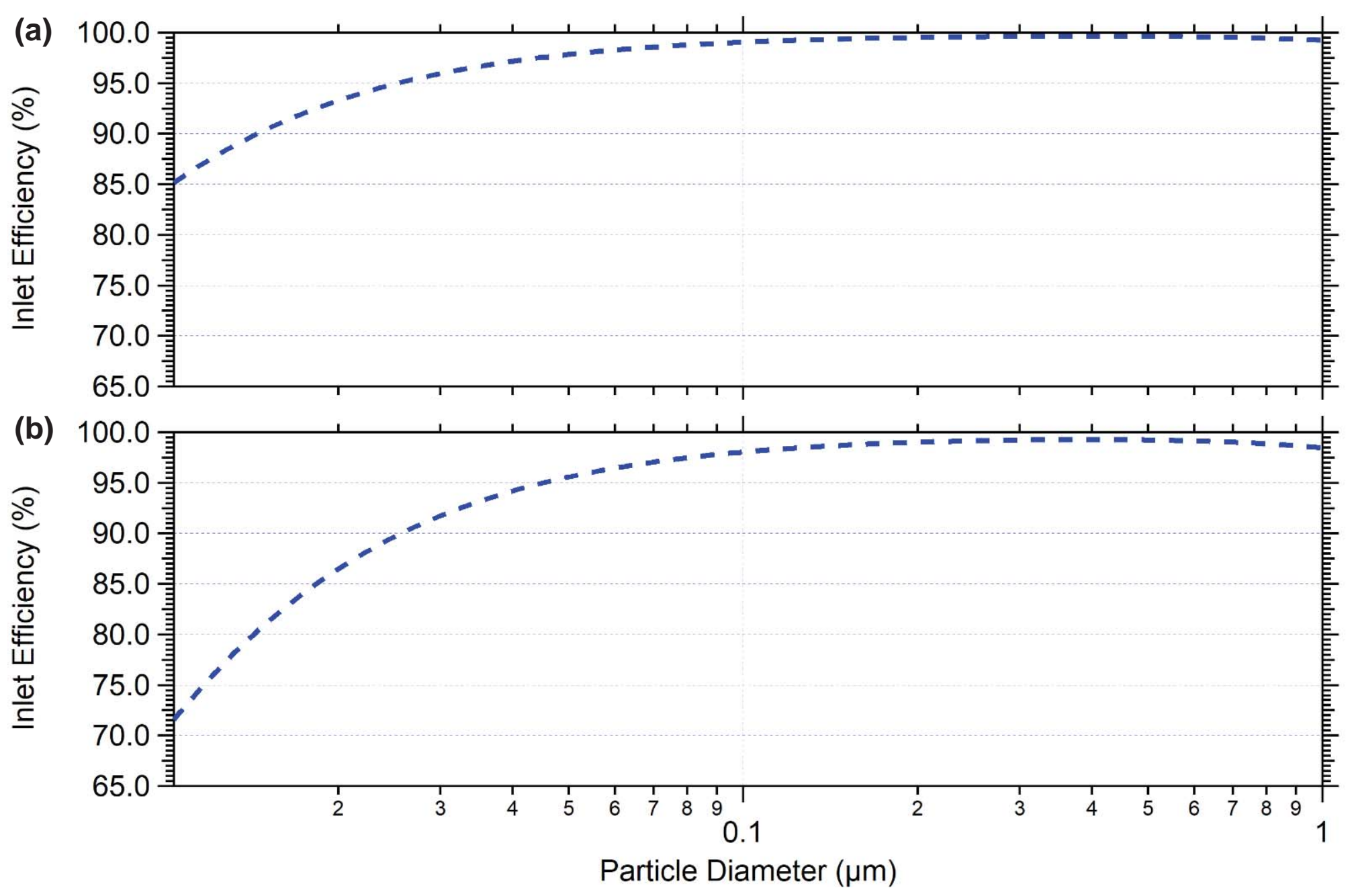

Figure S1. Inlet particle transmission efficiency for the AMS (a) and SMPS (b) at the PEARL RigdeLab. Note that the curves do not include the instrument transmission efficiencies for the AMS (Jayne et al. Aerosol Sci. Technol. 2000, 33, 49-70) or for the SMPS (Wiedensohler et al. Atmos. Meas. Tech. 2012, 5, 657-685). 
(a)

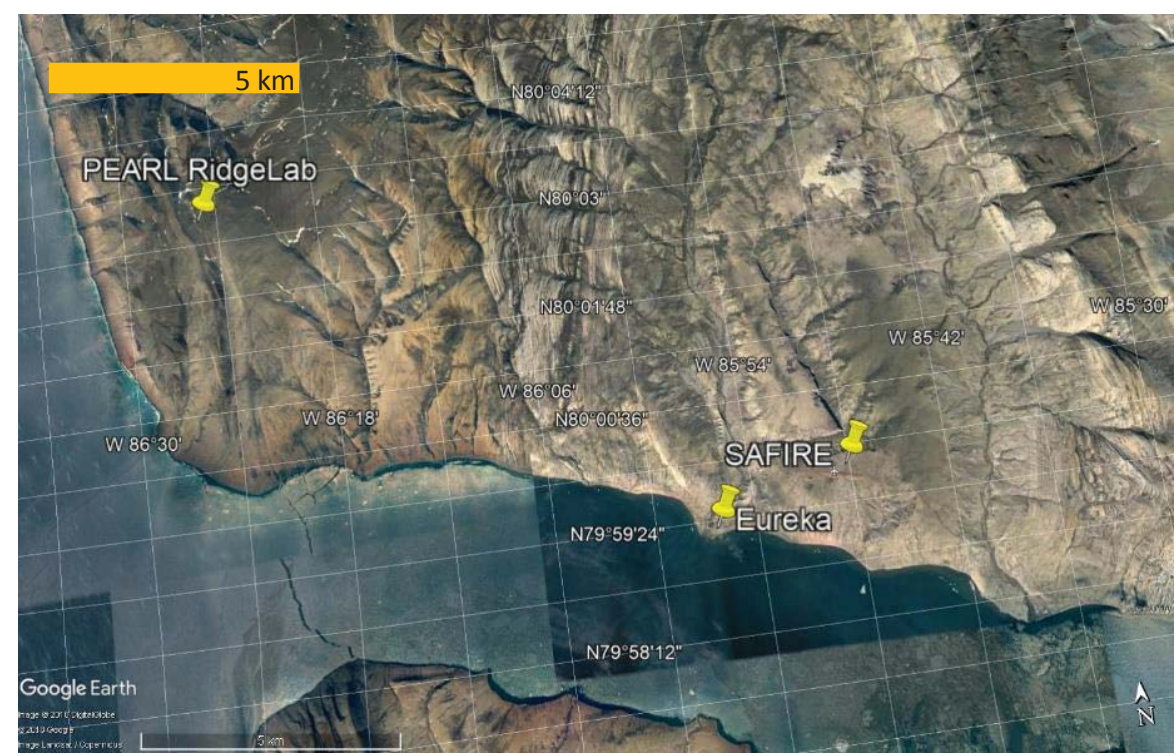

(b)

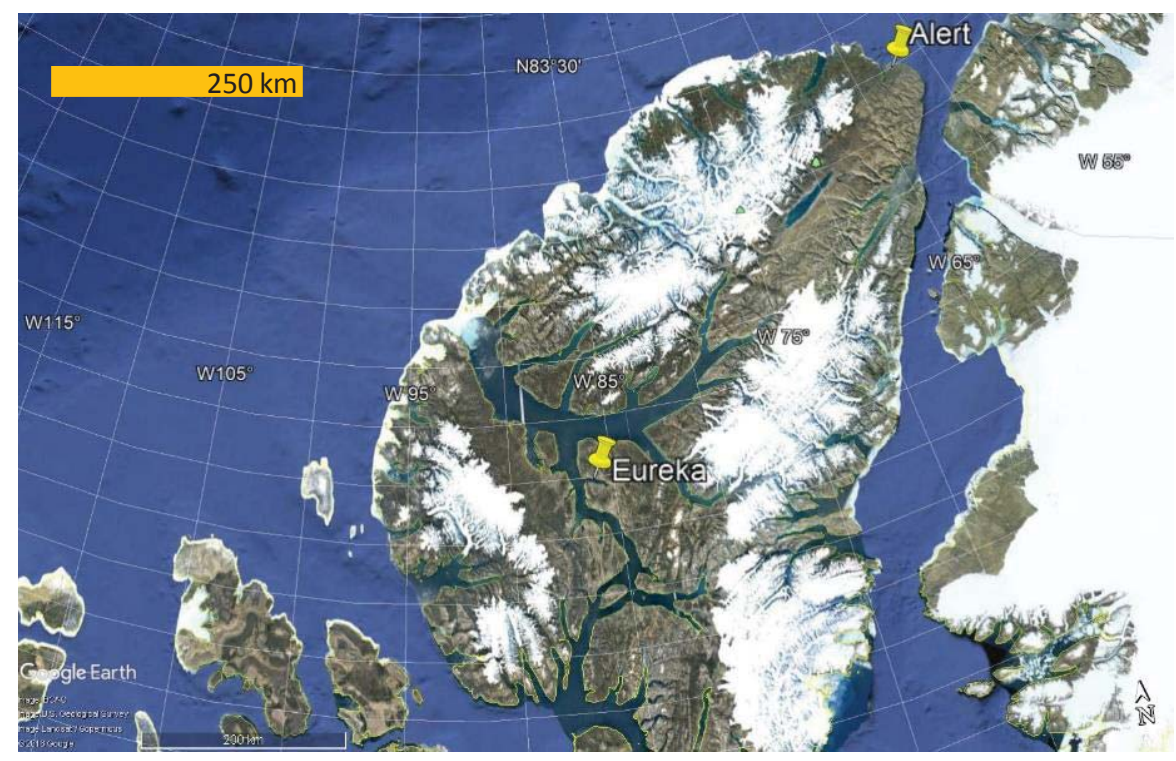

Figure S2. Local map of PEARL RidgeLab, SAFIRE and Eureka weather station (a) and zoomed-out map of Alert and Eureka (b). 

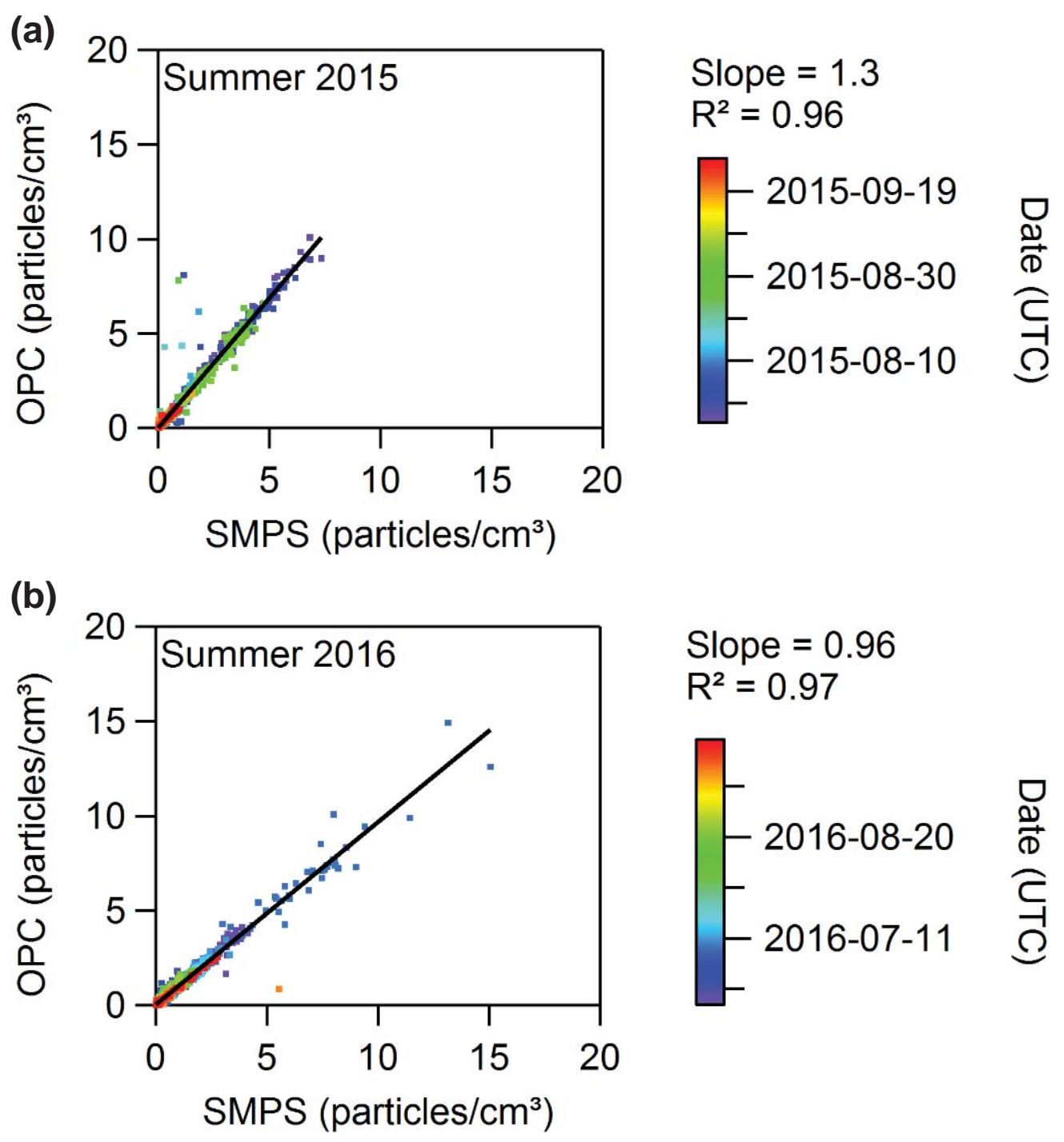

Figure S3. Scatter plots of the hourly particle number concentrations measured by the SMPS (300 - 487 $\mathrm{nm}$ ) and the OPC (300-500 nm) near Eureka for the summers of 2015 (26 July to 26 September 2015) (a) and 2016 (16 June to 26 September 2016) (b). 
GE 1

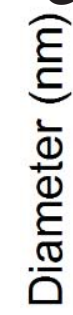

10
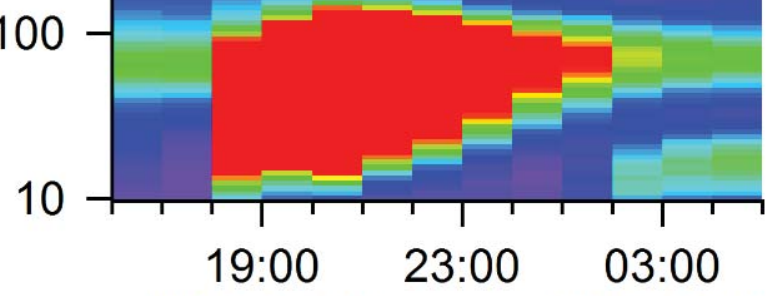

19:00

23:00

03:00

GE 3

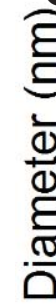

10 2015-07-27

2015-07-28

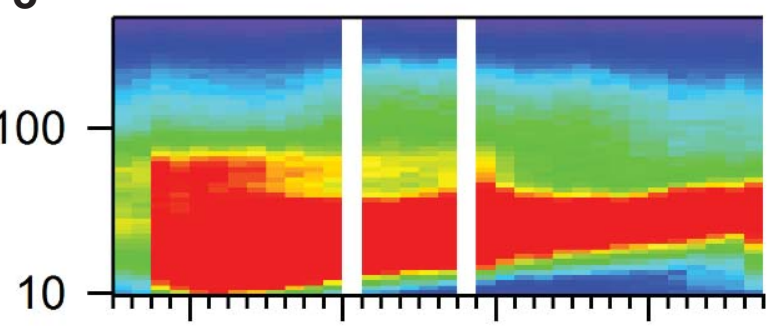

07:00 15:00 23:00 07:00 2015-07-29

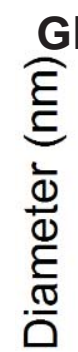

GE 6

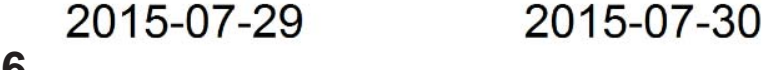

10
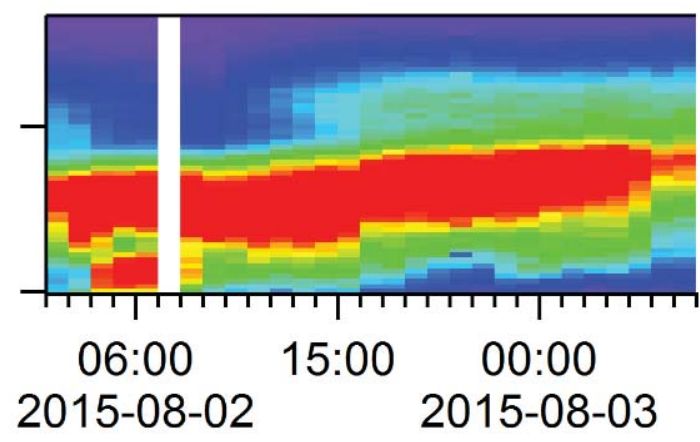

है

GE 9

10

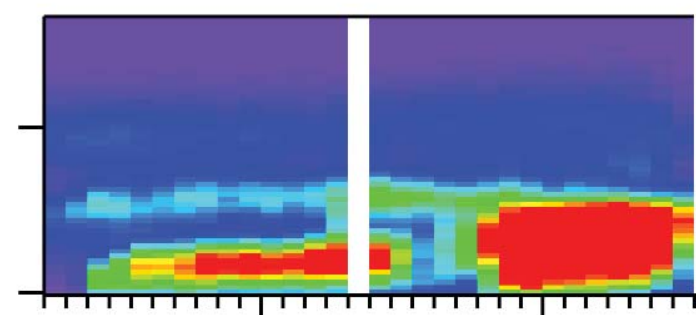

11:00 2015-08-07 2015-08-08

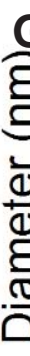

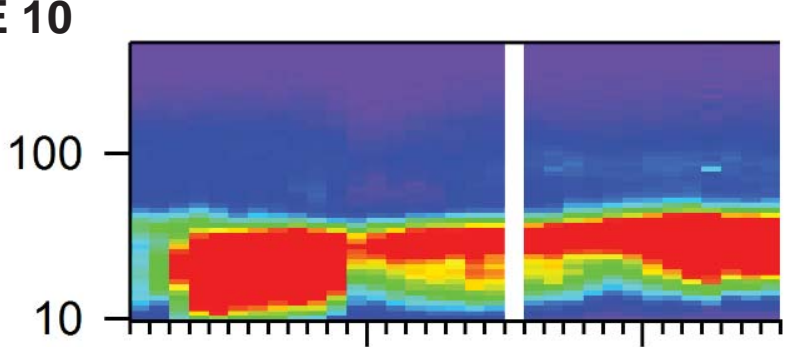

$\begin{array}{cc}07: 00 & 21: 00 \\ 2015-08-08 & \end{array}$

Date (UTC)

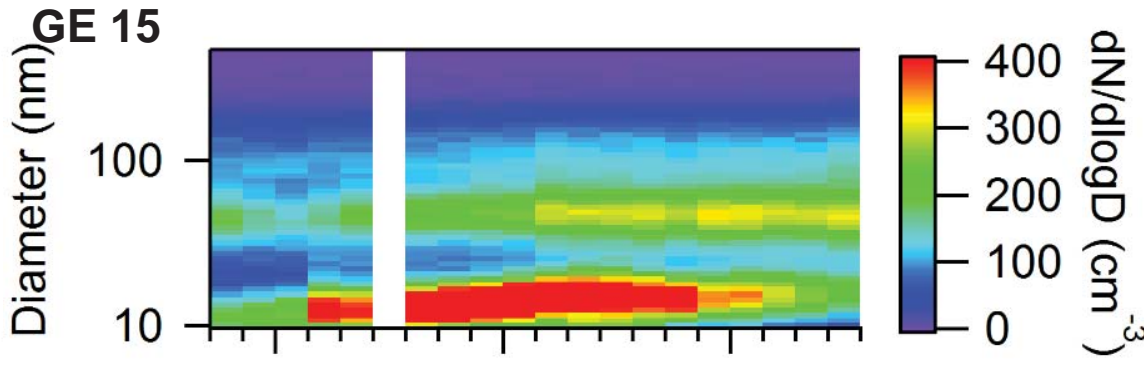

12:00 19:00 02:00 2015-08-18 2015-08-19

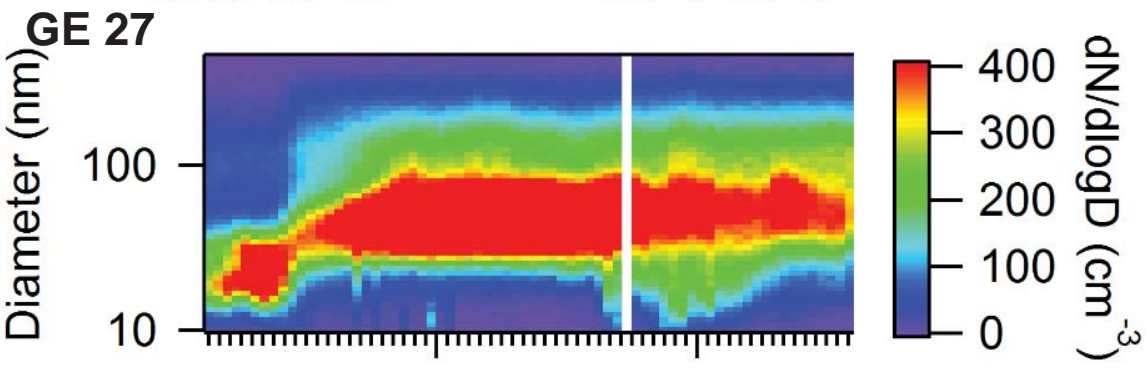

GE 28

2016-06-15 2016-06-17
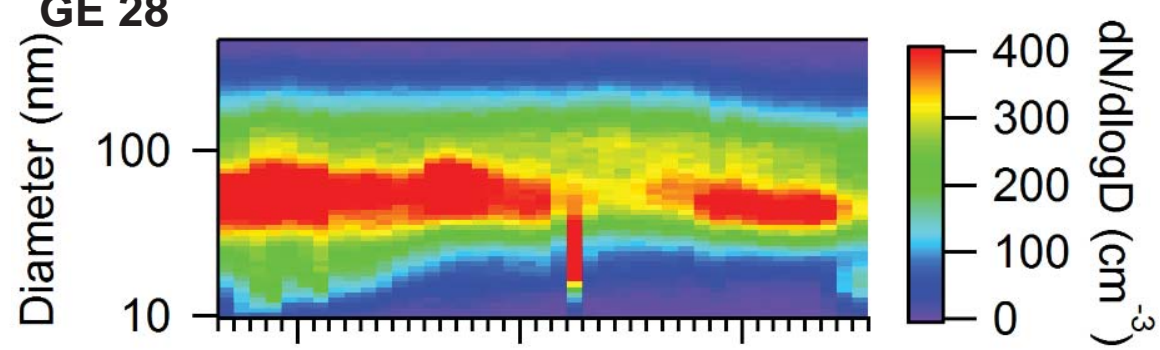

03:00 17:00 07:00

GE 30

2016-06-17

2016-06-18
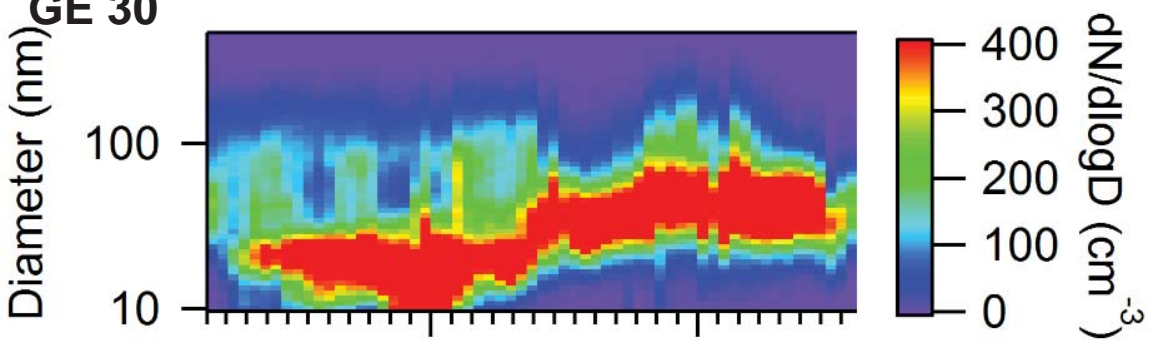

00:00

01:00

2016-06-26 2016-06-27
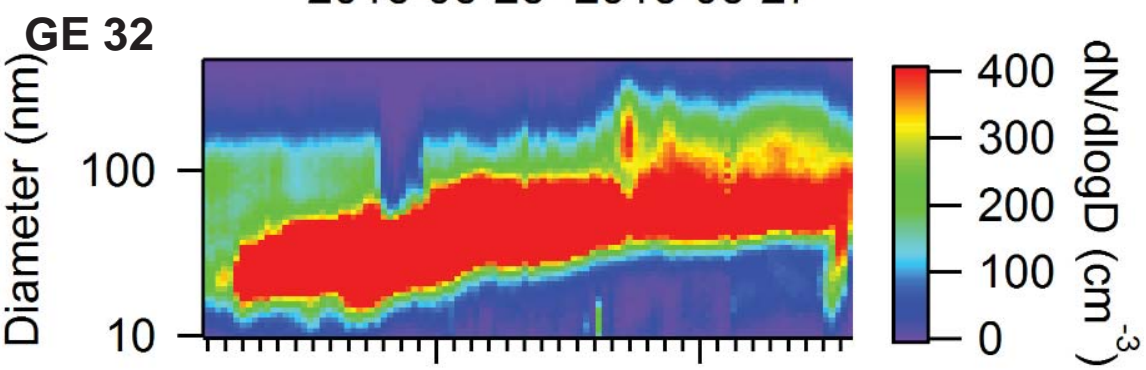

15:00

10:00

2016-07-05 2016-07-07

Date (UTC)

Figure S4. SMPS measurements of each growth event observed near Eureka during the summers of 2015 and 2016 as summarized in Table S1. The sizes are mobility diameters measured by an SMPS, which are equal to the physical diameters under the assumption that the particles were spherical and contained no voids. 
GE 33

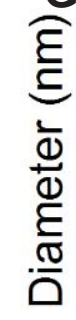

10

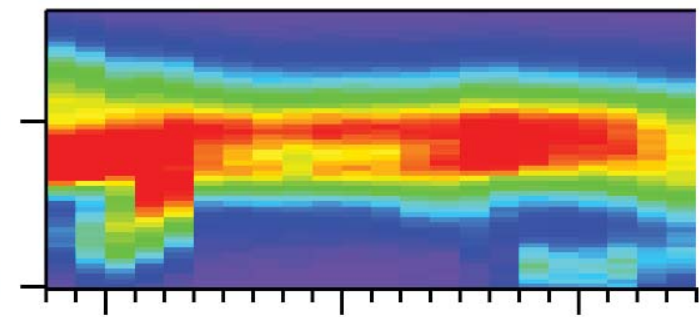

07:00 15:00 23:00 2016-07-08

GE 34

है

10

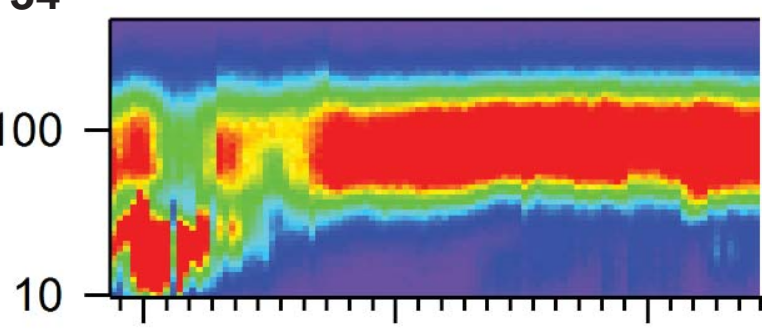
23:00 13:00

03:00

2016-07-09 2016-07-11 2016-07-13

GE 37

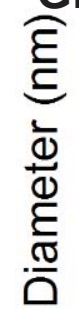

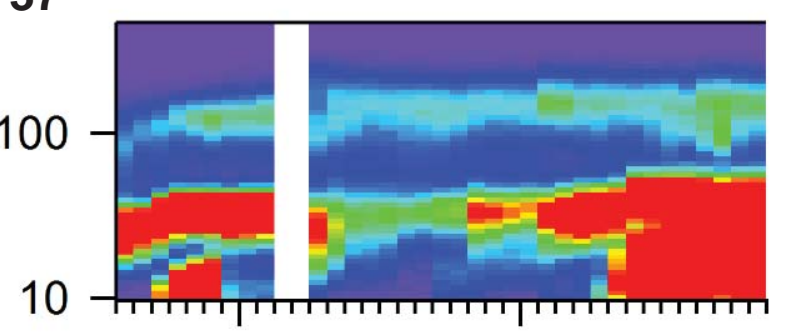

23:00

15:00

2016-07-20 2016-07-21

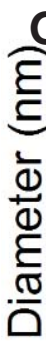

GE 38

10

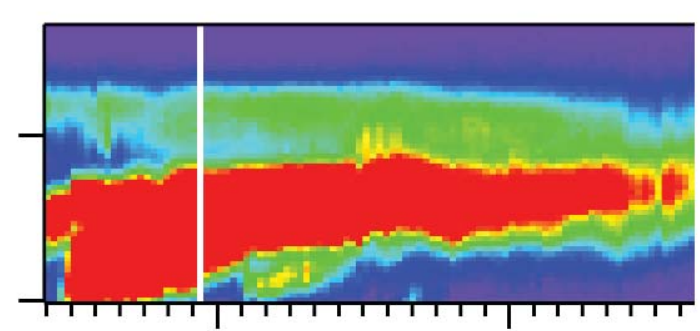

19:00

15:00

2016-07-22 2016-07-24

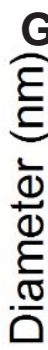

GE 39

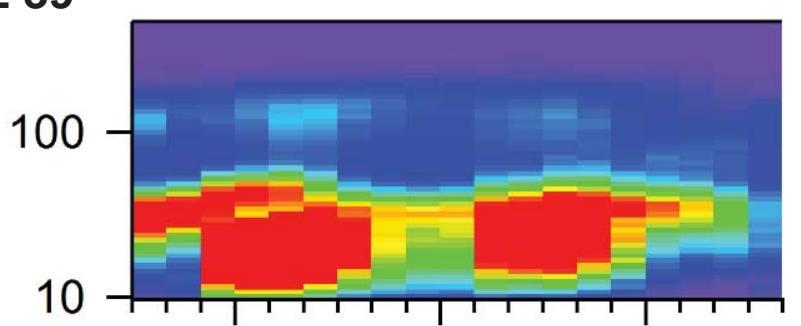

$03: 00$
2016-07-27

Date (UTC)
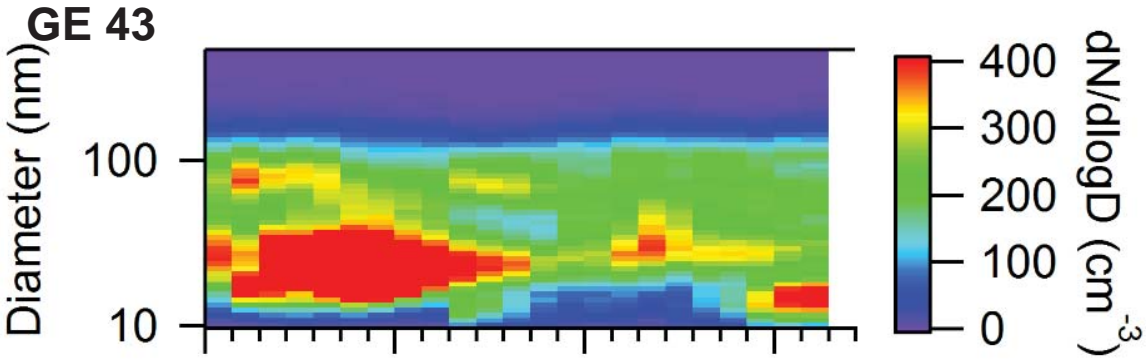

$\begin{array}{ccc}16: 00 & 23: 00 & 06: 00 \\ 2016-08-04 & 13: 00\end{array}$
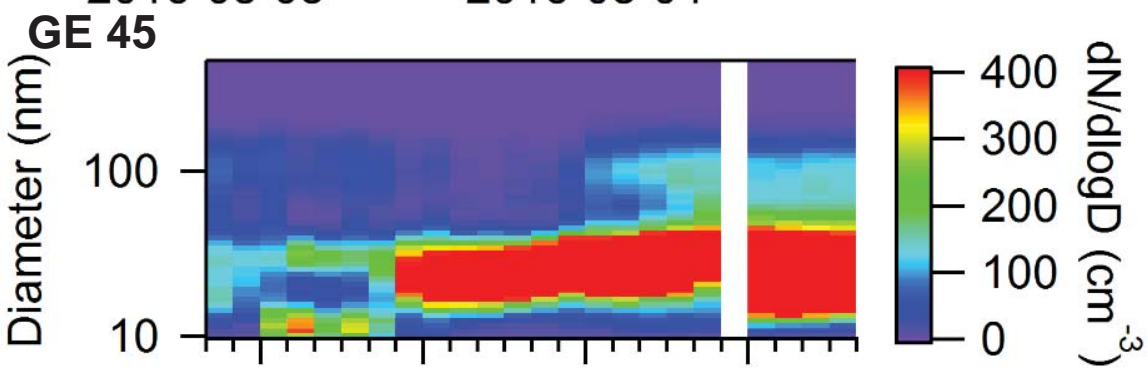

\section{3:00 09:00 15:00 21:00} 2016-08-05

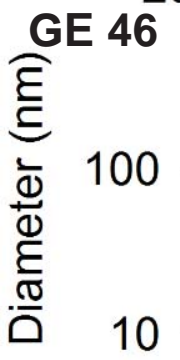

GE 46
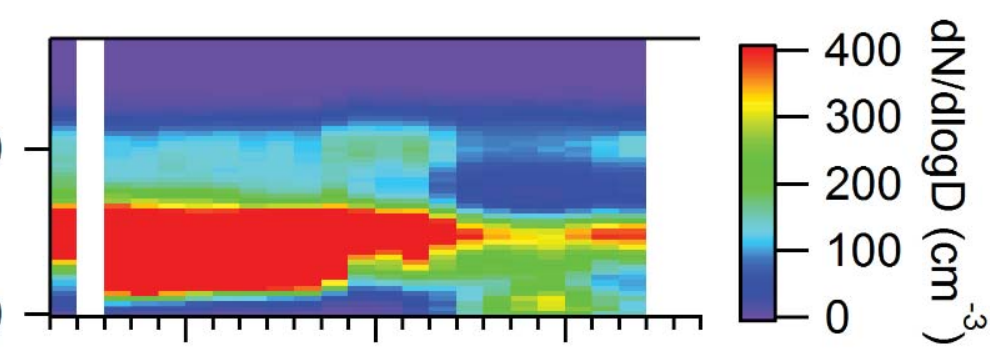

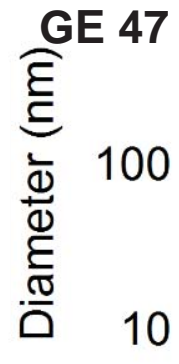

00:00 07:00 14:00
$2016-08-06$

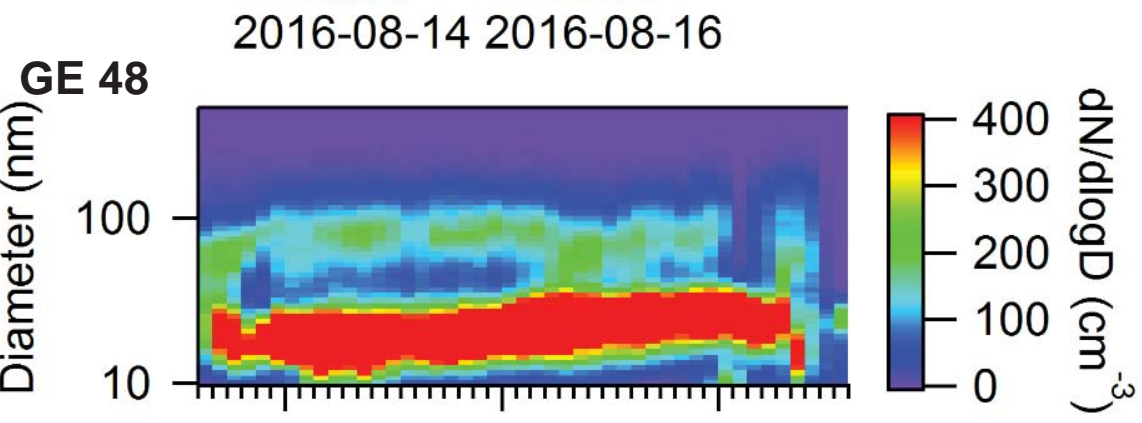

$$
\begin{array}{ccc}
\text { 03:00 } & 18: 00 & 09: 00 \\
2016-08-18 & & 2016-08-19
\end{array}
$$

Date (UTC)
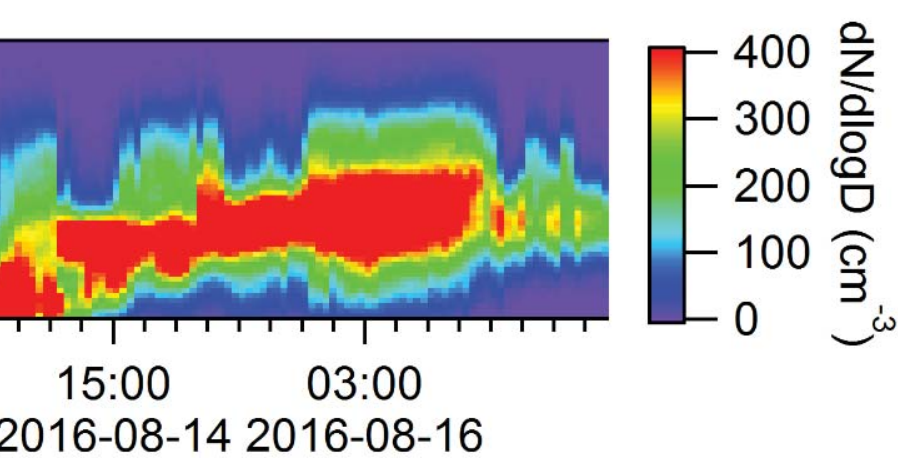

Figure S4. SMPS measurements of each growth event observed near Eureka during the summers of 2015 and 2016 as summarized in Table S1 (continued). The sizes are mobility diameters measured by an SMPS, which are equal to the physical diameters under the assumption that the particles were spherical and contained no voids. 
GE 49

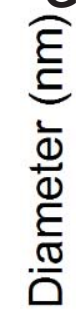

10

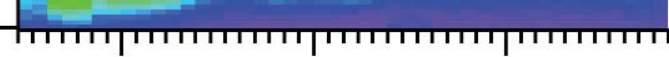

04:00 17:00 06:00 2016-08-21 2016-08-22

GE 51

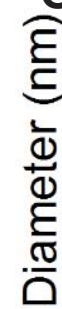

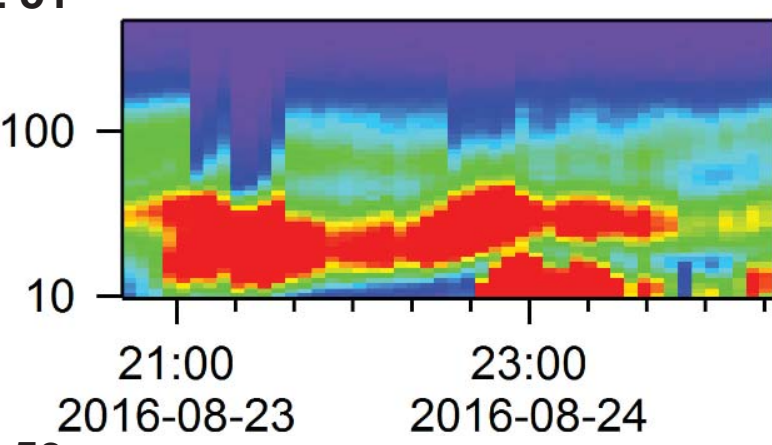

GE 53

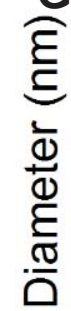

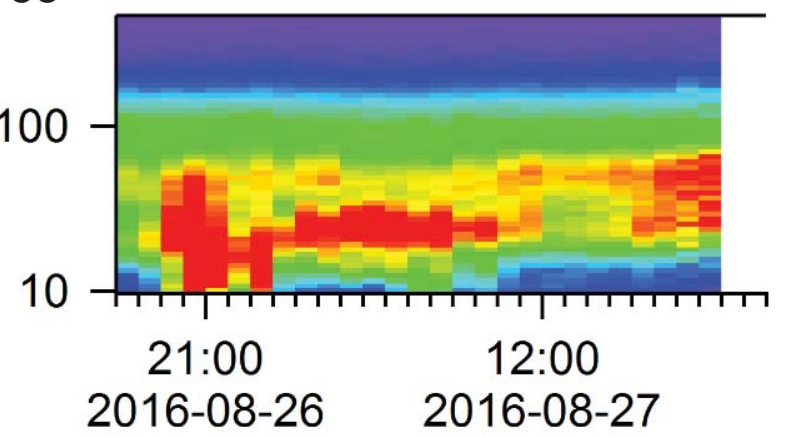

GE 54

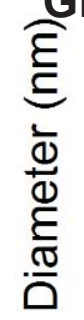

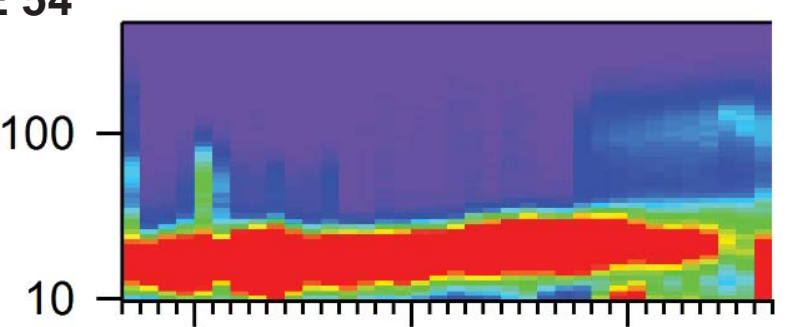

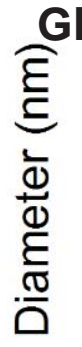

GE 55

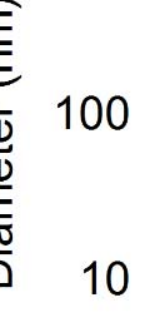

10
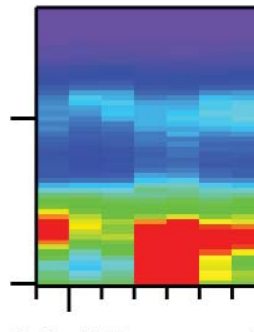

08:00

15:00

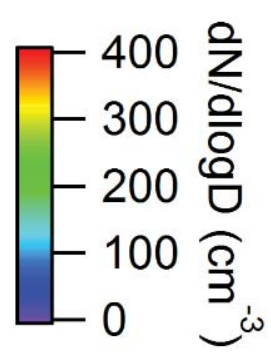

\section{GE 56}
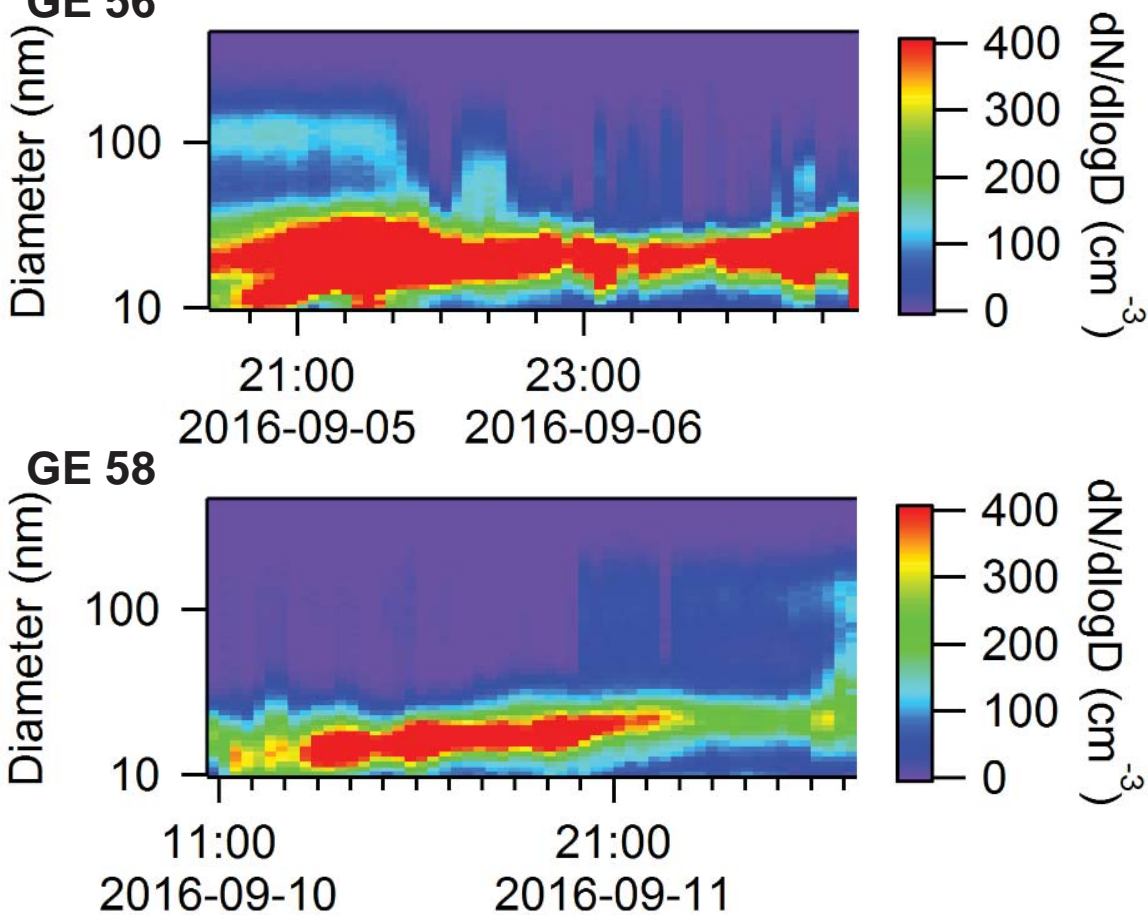
2016-09-11

$$
\begin{array}{ccc}
03: 00 & 15: 00 & 03: 00 \\
2016-09-04 & & 2016-09-05
\end{array}
$$

Date (UTC)

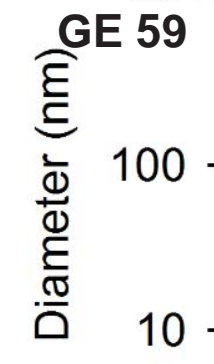

0

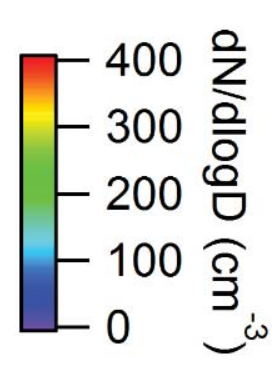

$$
\begin{array}{cc}
06: 00 \quad 15: 00 \quad 00: 00 \\
2016-09-19 \quad 2016-09-20
\end{array}
$$

Date (UTC)

Figure S4. SMPS measurements of each growth event observed near Eureka during the summers of 2015 and 2016 as summarized in Table S1 (continued). The sizes are mobility diameters measured by an SMPS, which are equal to the physical diameters under the assumption that the particles were spherical and contained no voids. 


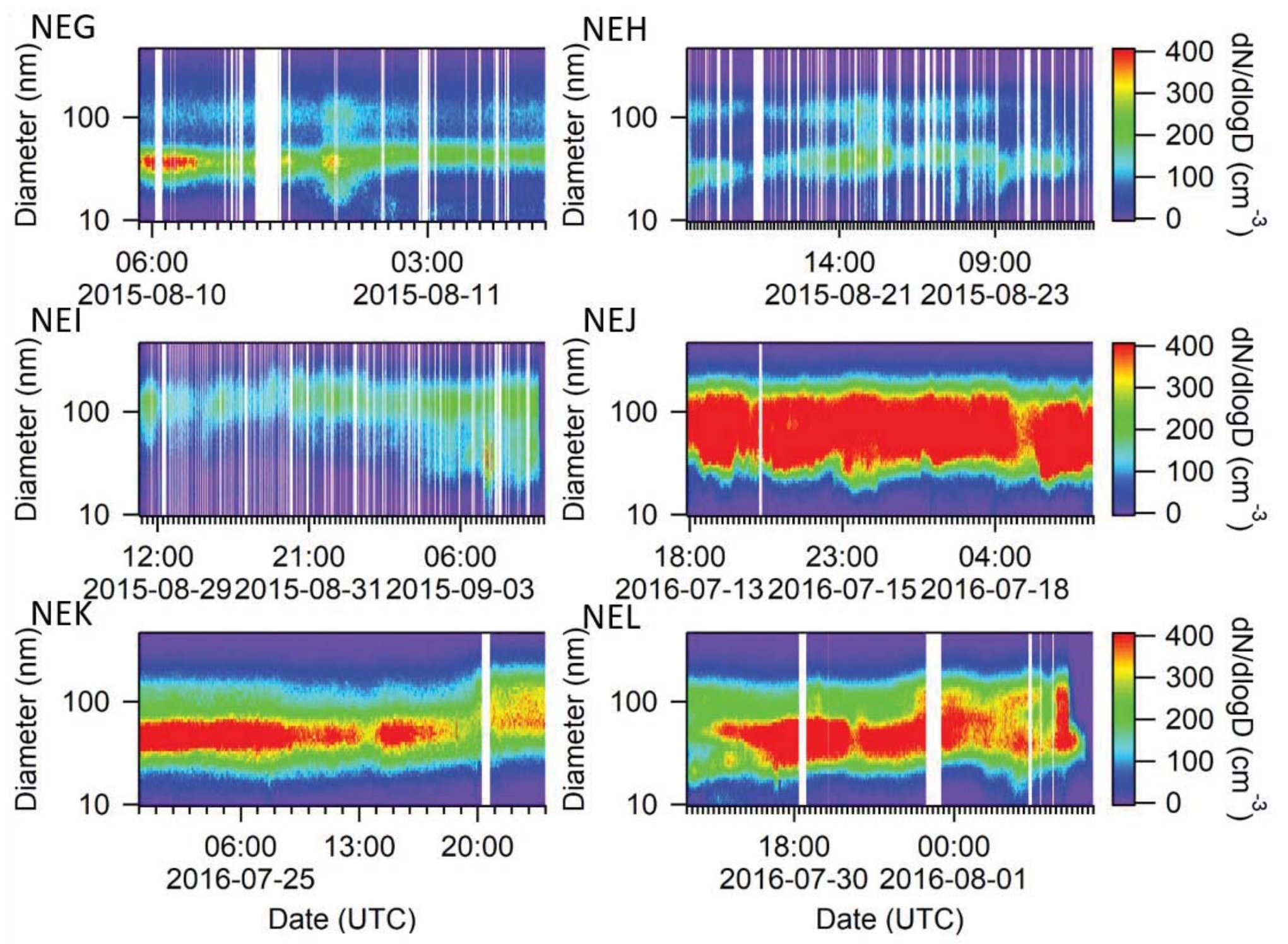

Figure S6. SMPS measurements of selected periods with high particle concentrations and without growth observed near Eureka during the summers of 2015 and 2016 as summarized in Table S2. Note that the figures display an additional 2 hours before and after the analyzed period. The sizes are mobility diameters measured by an SMPS, which are equal to the physical diameters under the assumption that the particles were spherical and contained no voids. 
GE 3 Eureka July 292015 - 05h

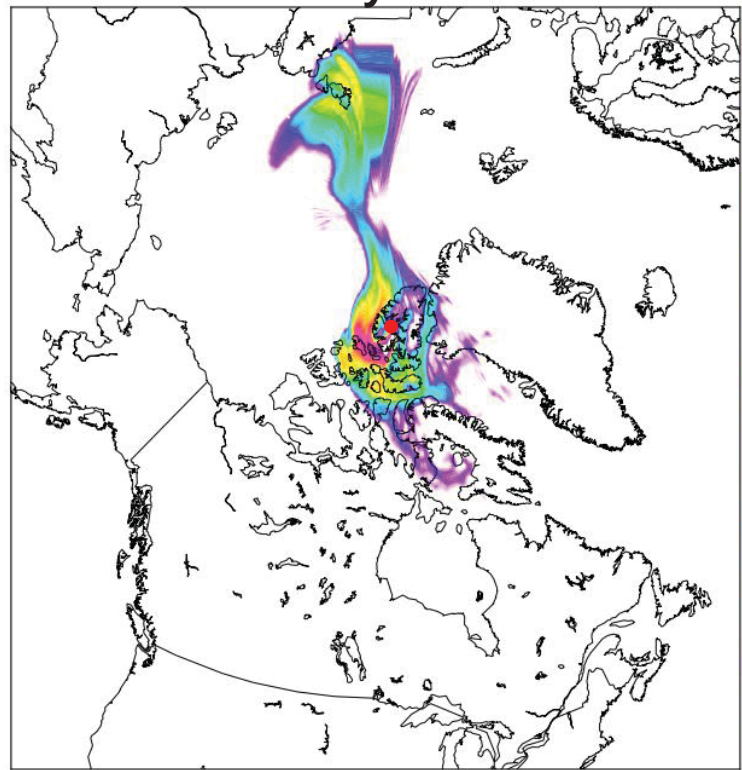

GE 6 Eureka August 022015 - 04h

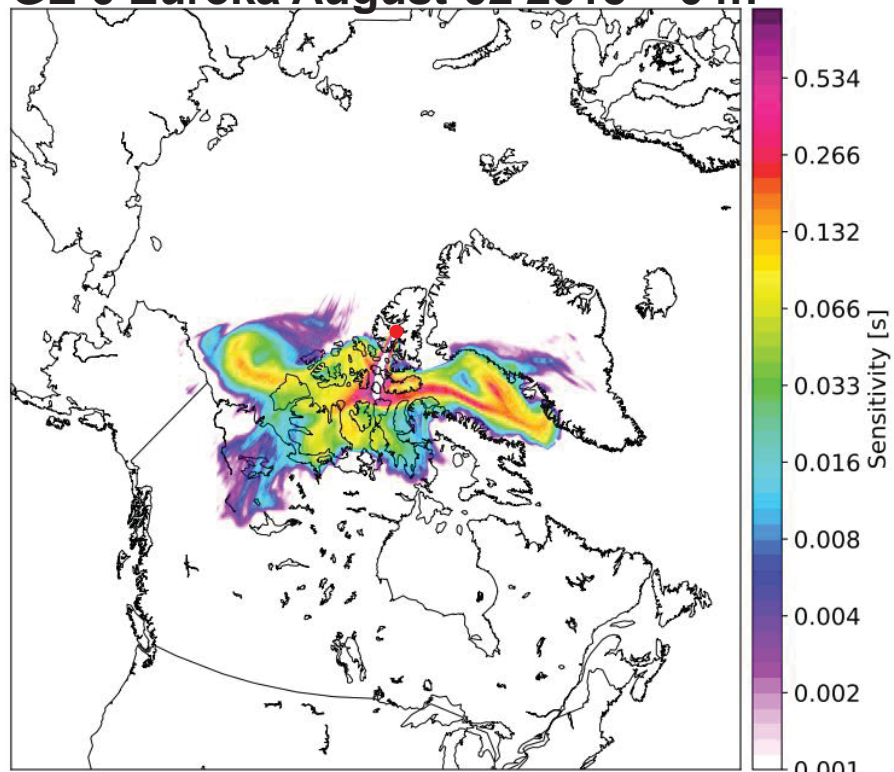

GE 30 Eureka June 252016 - 20h

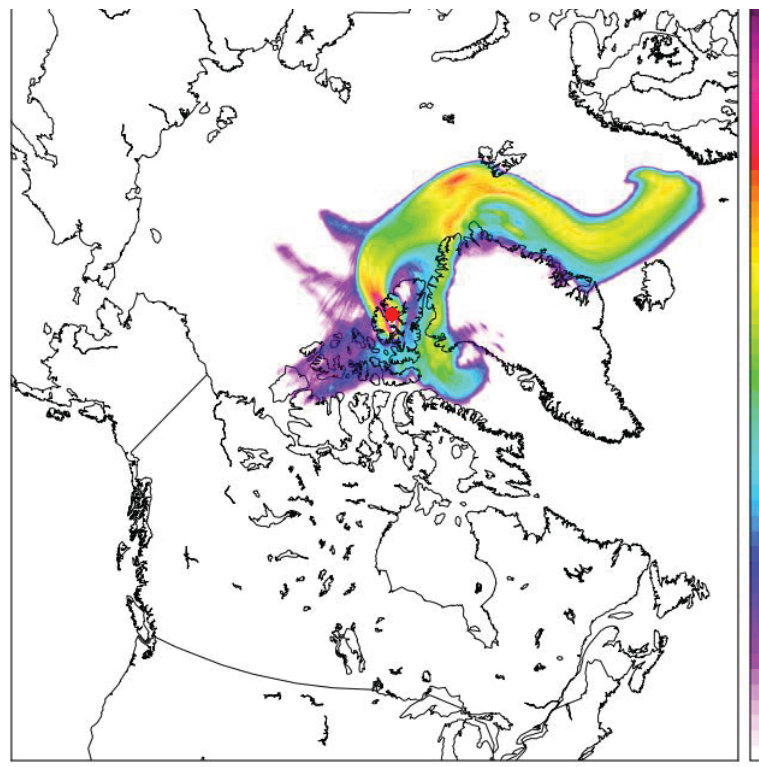

GE 3 Alert July 292015 - 03h

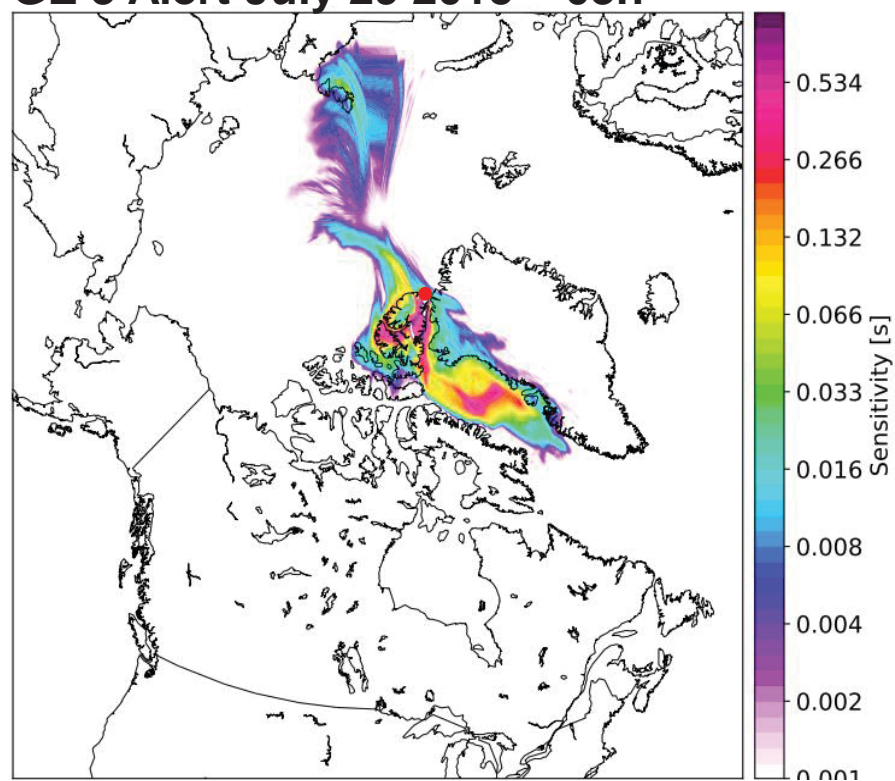

GE 30 Alert June $252016-20 h$

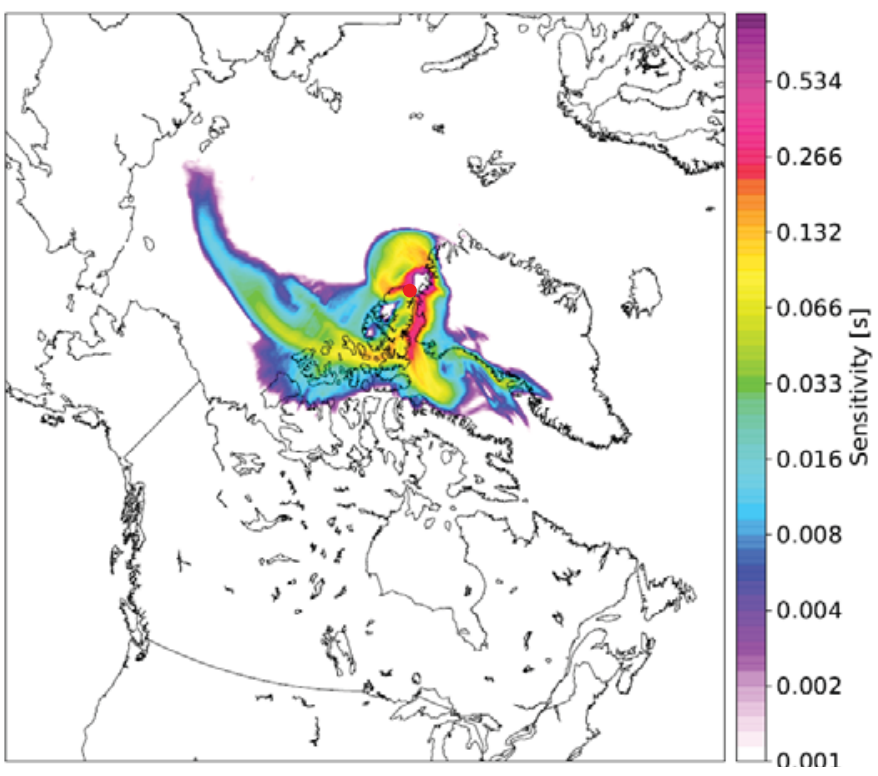

Figure S7. Evaluation of the air mass history during the five selected growth events summarized in Table 1 and shown in Figure 5 of the main text. The back-trajectory and potential emissions sensitivity were calculated using FLEXPART. The left column corresponds to air masses arriving at Eureka and the right column corresponds to those arriving at Alert. 
GE 32 Eureka July 052016 - 01h

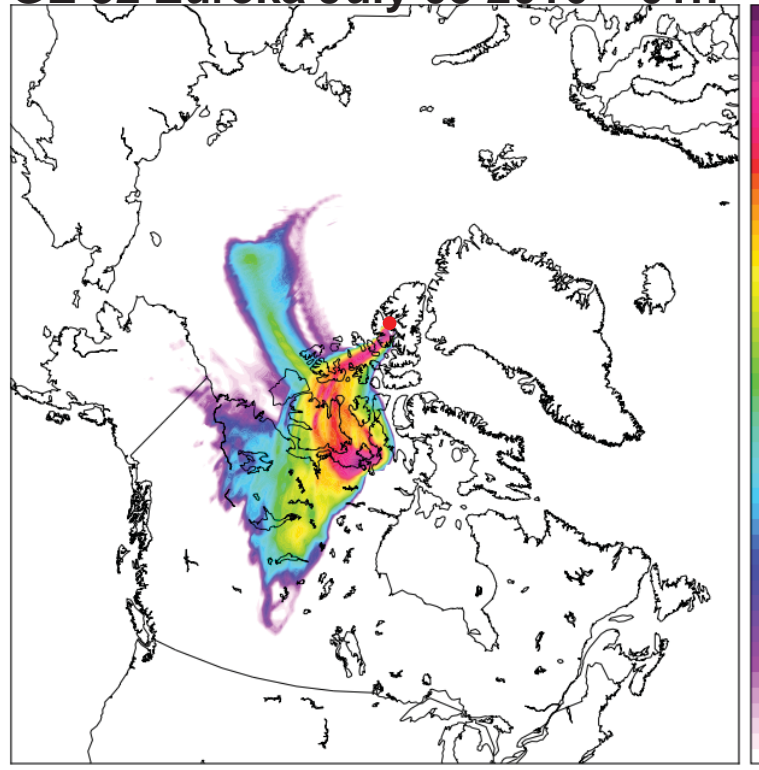

GE 38 Eureka July $212016-19 \mathrm{~h}$

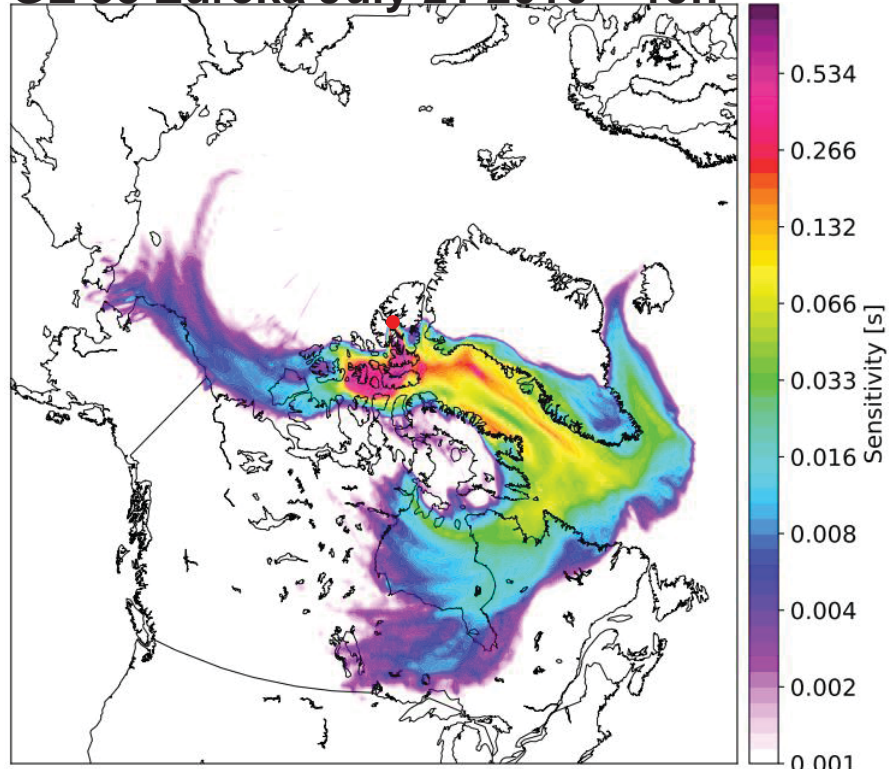

0.534

$-0.266$

0.132

0.066

0.033 .

0.016 ஸे

0.008

$-0.004$

0.002

ก กก1

GE 32 Alert July $042016-01 \mathrm{~h}$

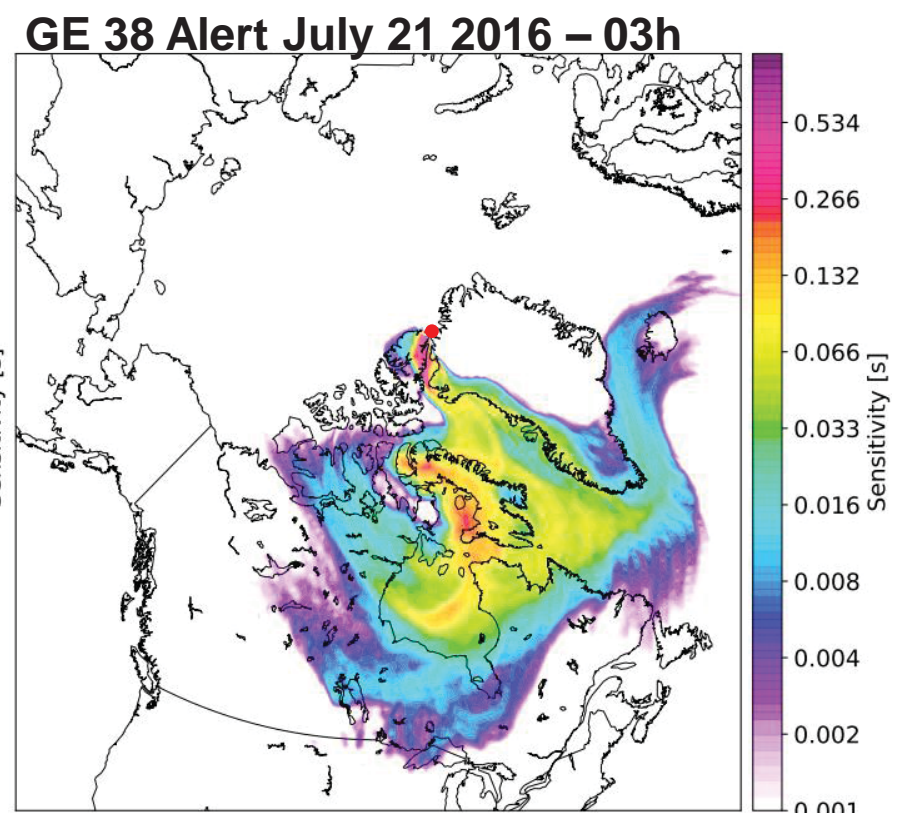

Figure S7. Evaluation of the air mass history during the five selected growth events summarized in Table 1 and shown in Figure 5 of the main text. The back-trajectory and potential emissions sensitivity were calculated using FLEXPART. The left column corresponds to air masses arriving at Eureka and the right column corresponds to those arriving at Alert (continued). 

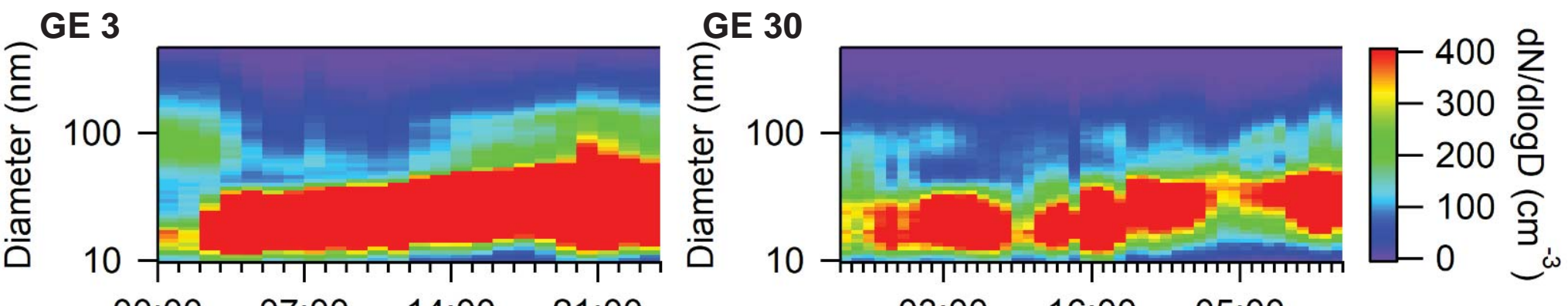

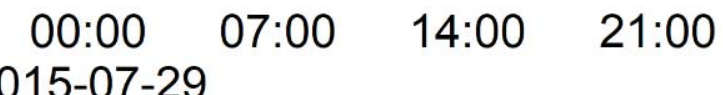

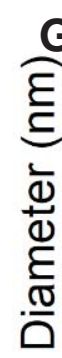
2015-07-29

GE 32

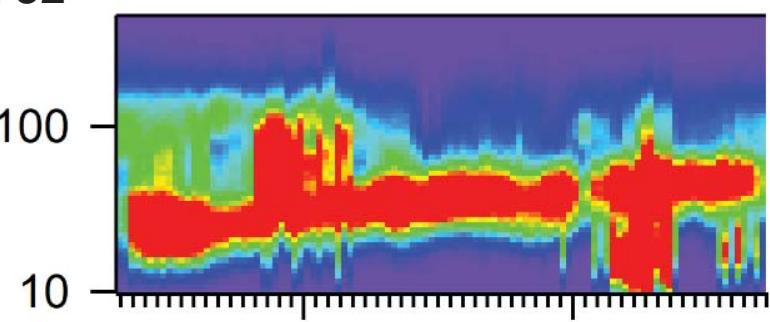

05:00 2016-07-05 2016-07-07

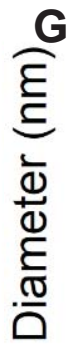

\section{3:00 16:00 05:00 \\ 2016-06-26 2016-06-27}

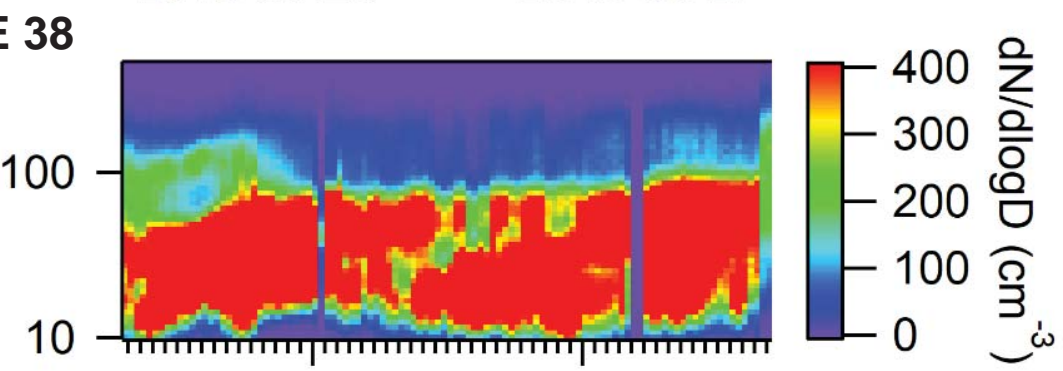

08:00

04:00

2016-07-22 2016-07-24

Figure S8. SMPS measurements of 4 growth events at Alert during the summers of 2015 and 2016 corresponding to the periods summarized in Table 1 . The sizes are mobility diameters measured by an SMPS, which are equal to the physical diameters under the assumption that the particles were spherical and contained no voids. 
(a)

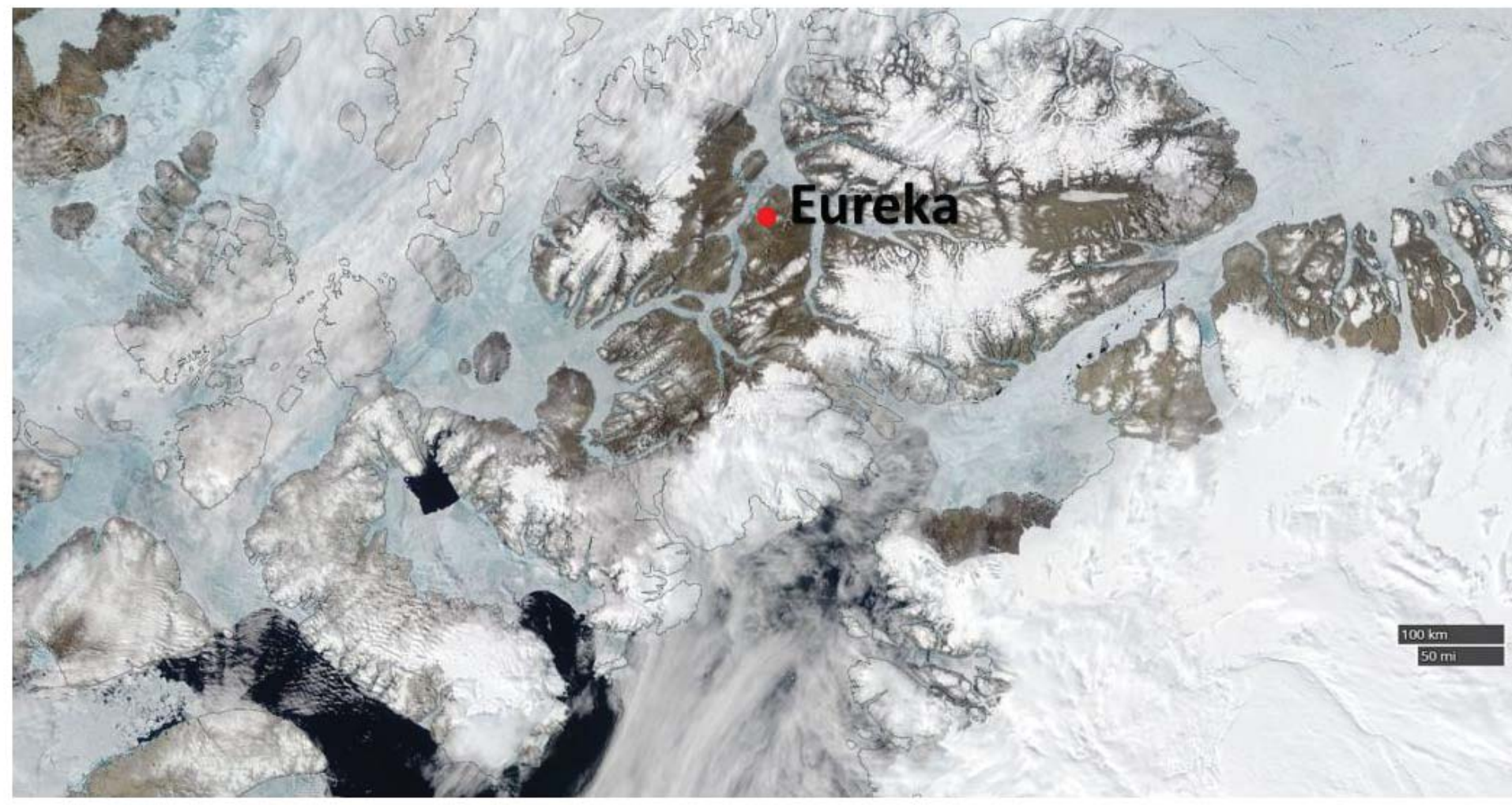

(b)

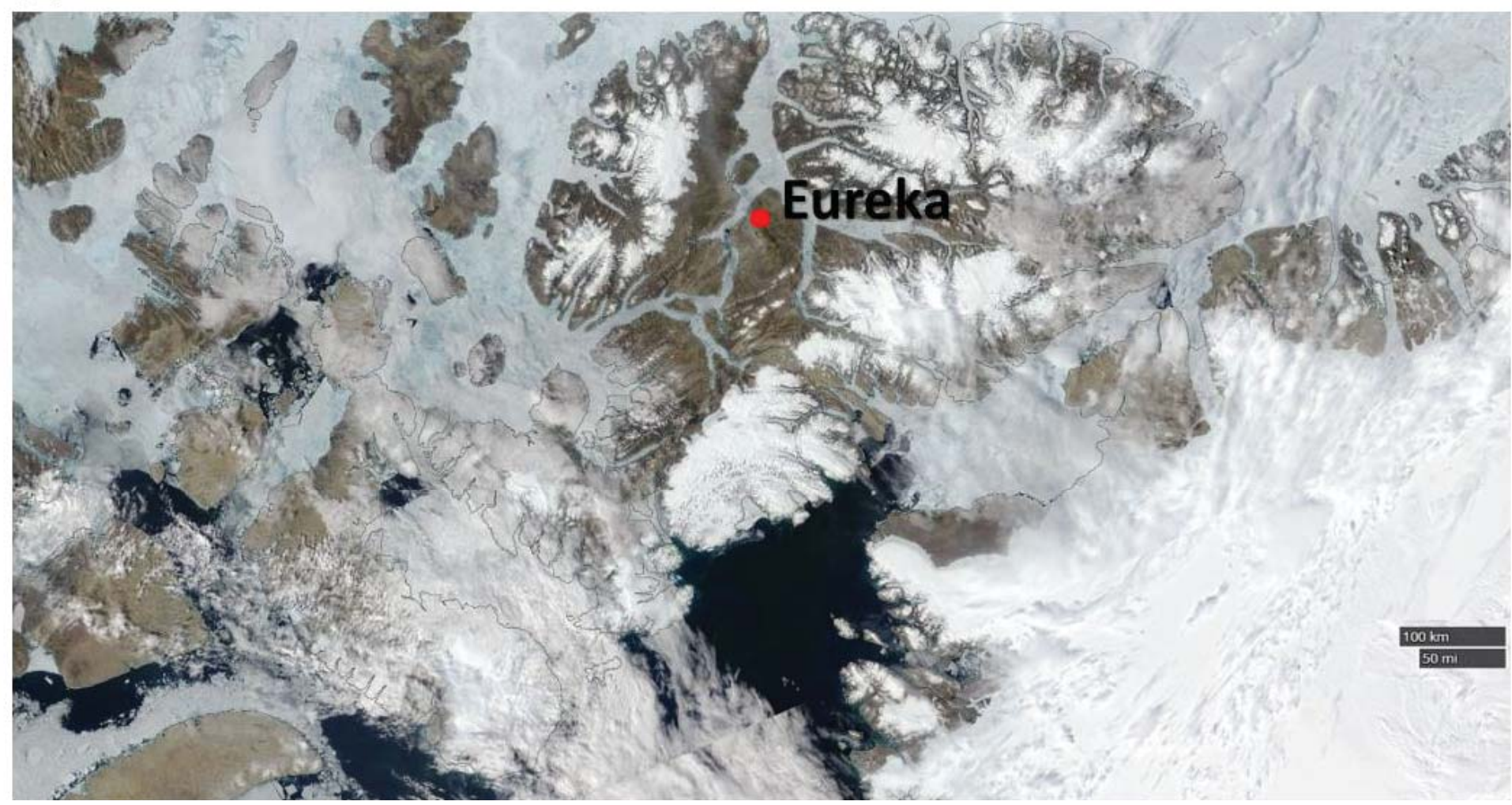

Figure S9. Image of the ice coverage around Eureka during 25 June 2016 (a) and during 7 July 2016 (b) as shown in MODIS imagery accessed by NASA Worldview. 
NEA Eureka August 062015 - 06h

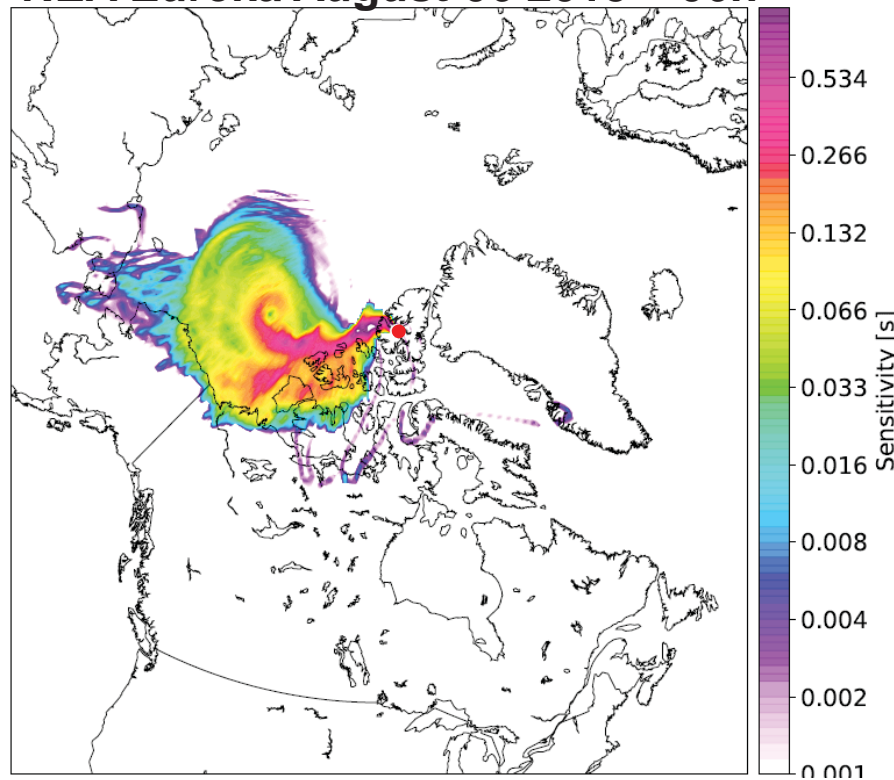

NEC Eureka September 042015 - 12h

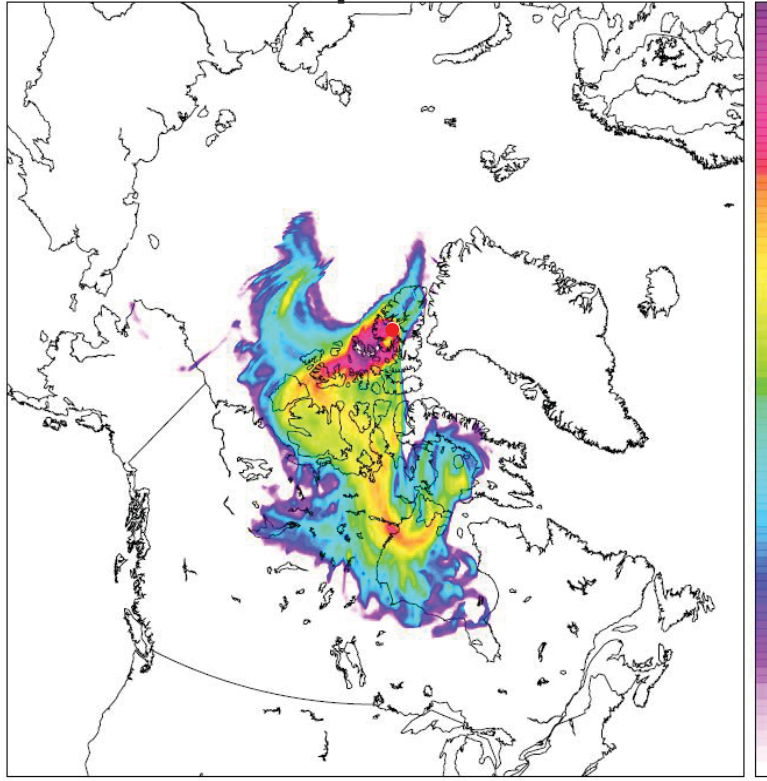

NEE Eureka June 302016 - 12h
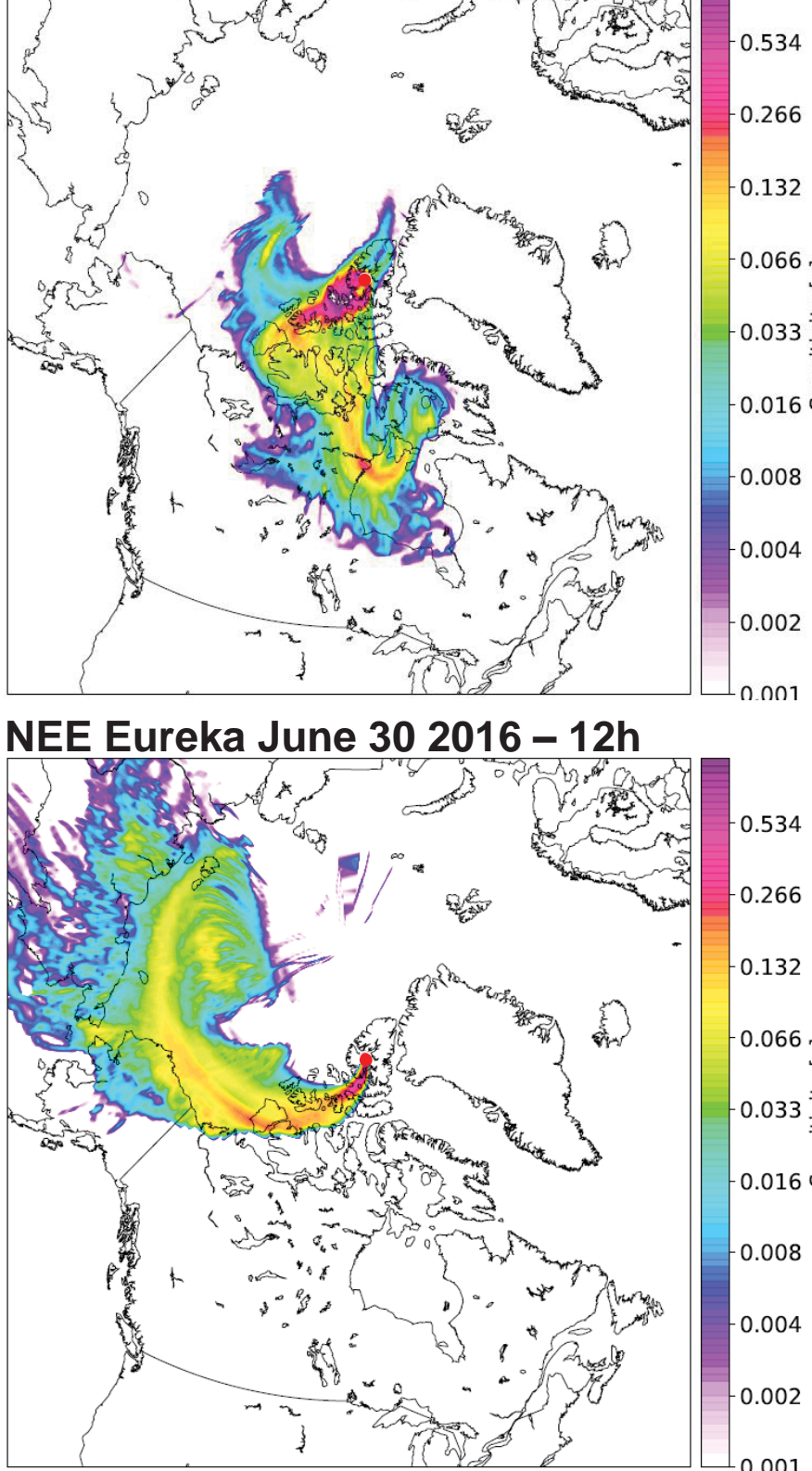

NEB Eureka August 242015 - 11h

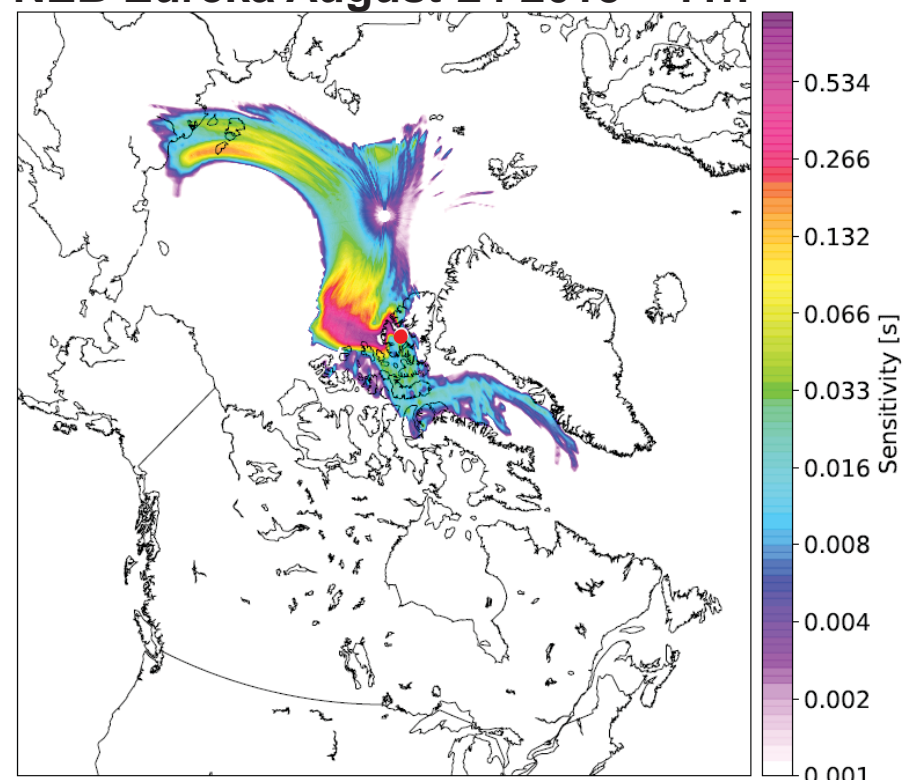

NED Eureka June 232016 - 08h

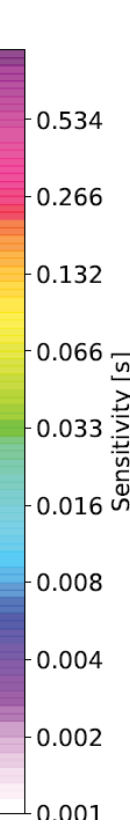

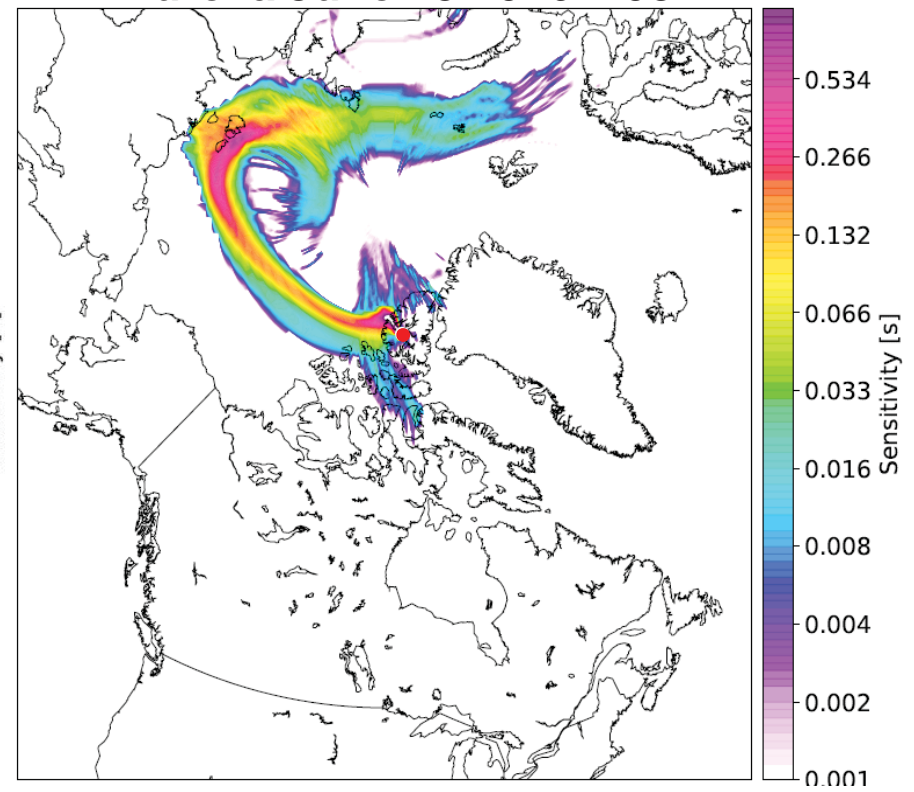

NEF Eureka August 022016 - 00h

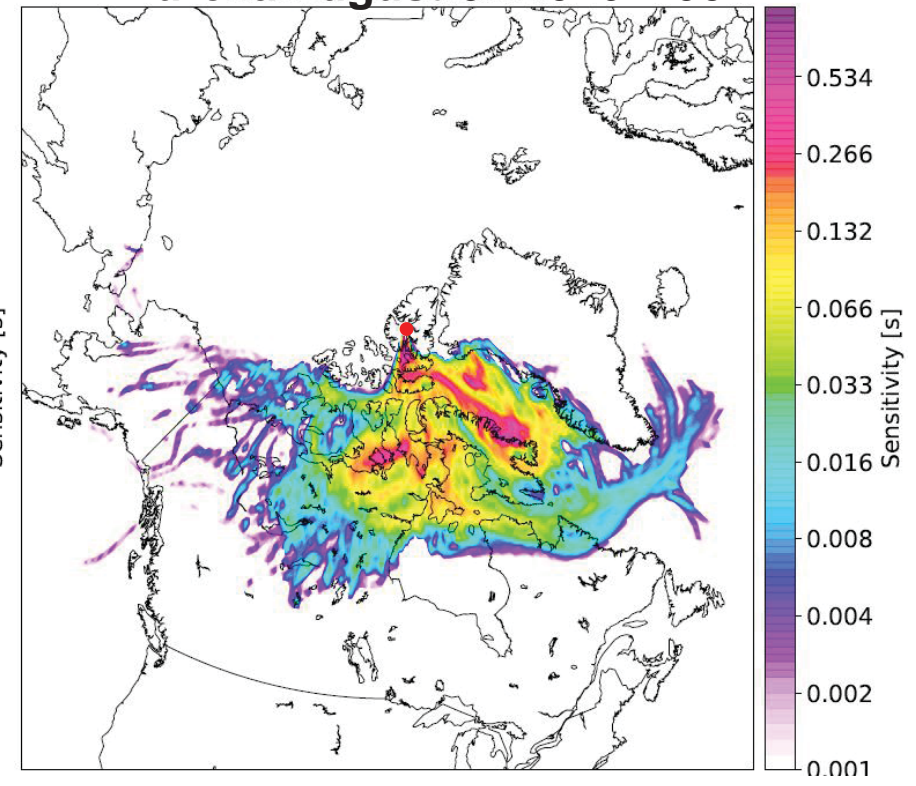

Figure S10. Evaluation of the air mass history during the low particle concentration events summarized in Table S2 and shown in Figure S5. The back-trajectory and potential emissions sensitivity were calculated using FLEXPART. 
NEG Eureka August 102015 - 07h

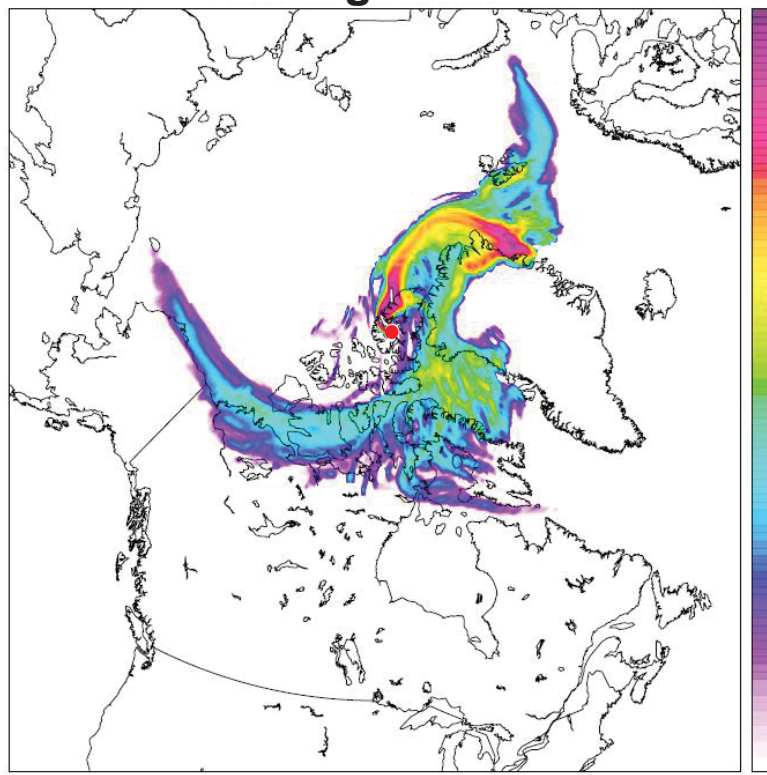

NEI Eureka August 292015 - 07h

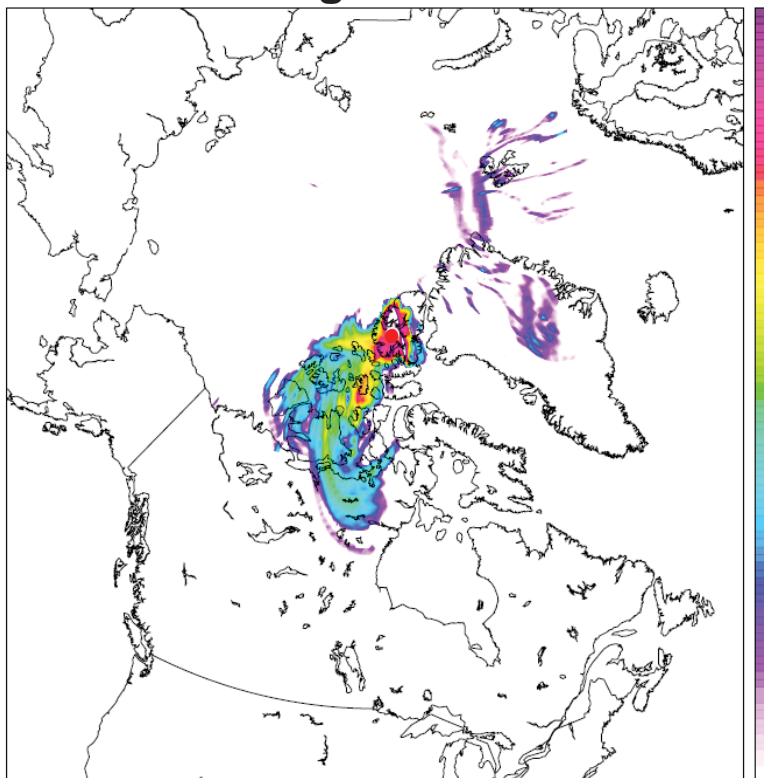

NEK Eureka July 252016 - 18h

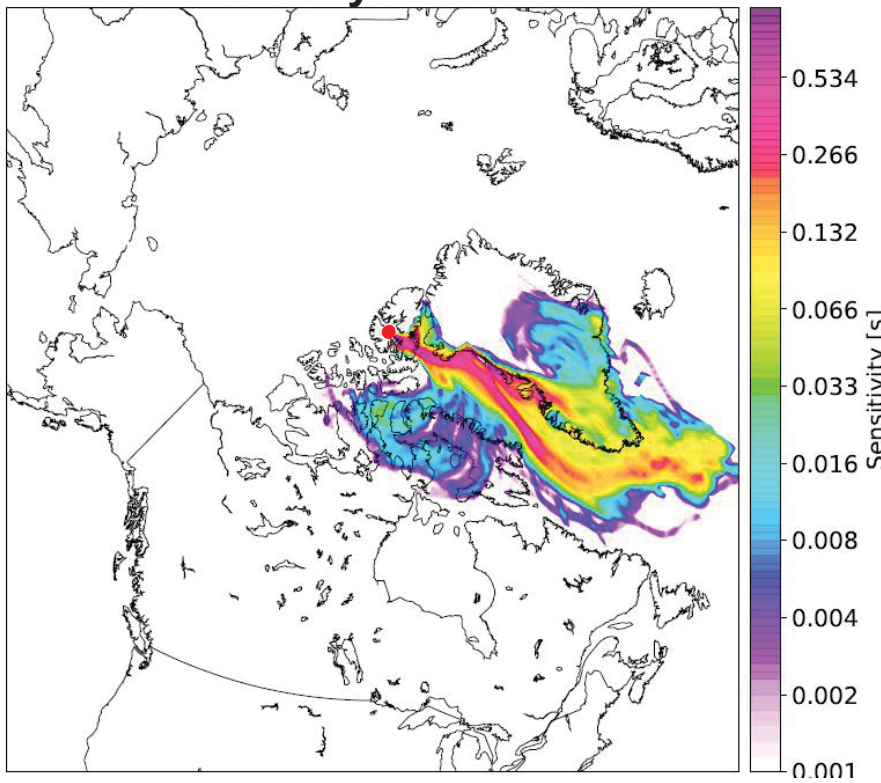

$-0.534$

$-0.266$

$-0.132$

$-0.033 \stackrel{2}{2}$

$-0.008$

$-0.004$

$-0.002$

ก.กก1

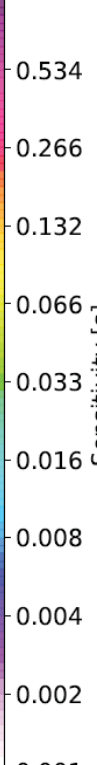

NEH Eureka August 192015 - 22h

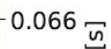

-0.016 ผें

NEL Eureka July 302016 - 00h

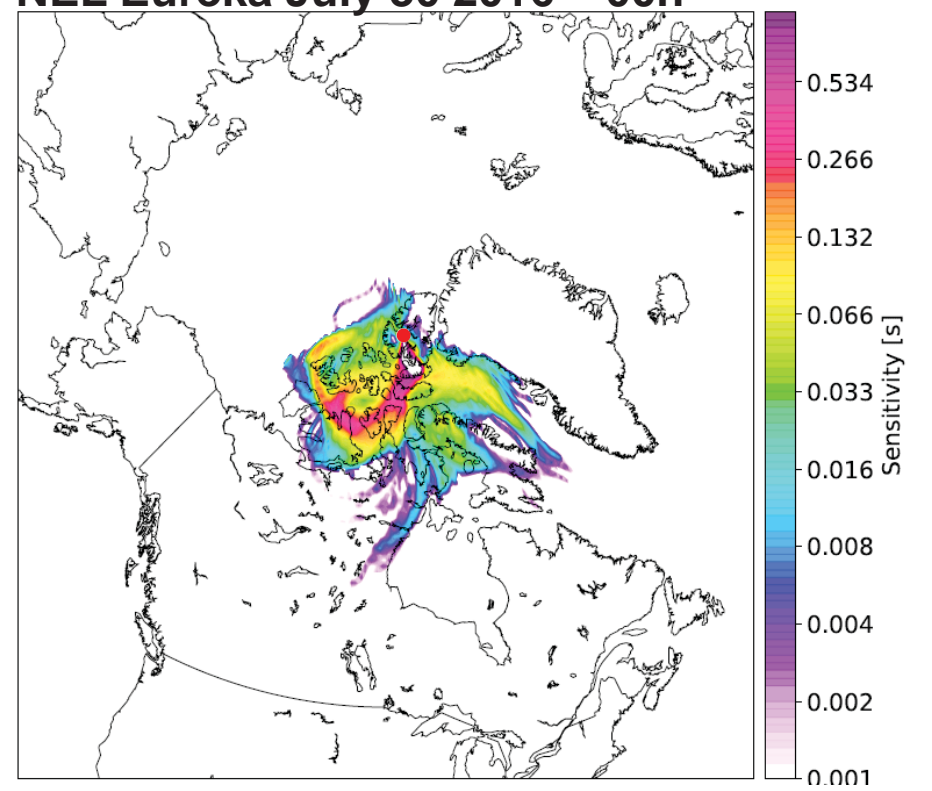

Figure S11. Evaluation of the air mass history during events with high particle concentrations and without growth summarized in Table S2 and shown in Figure S6. The back-trajectory and potential emissions sensitivity were calculated using FLEXPART. 
(a)

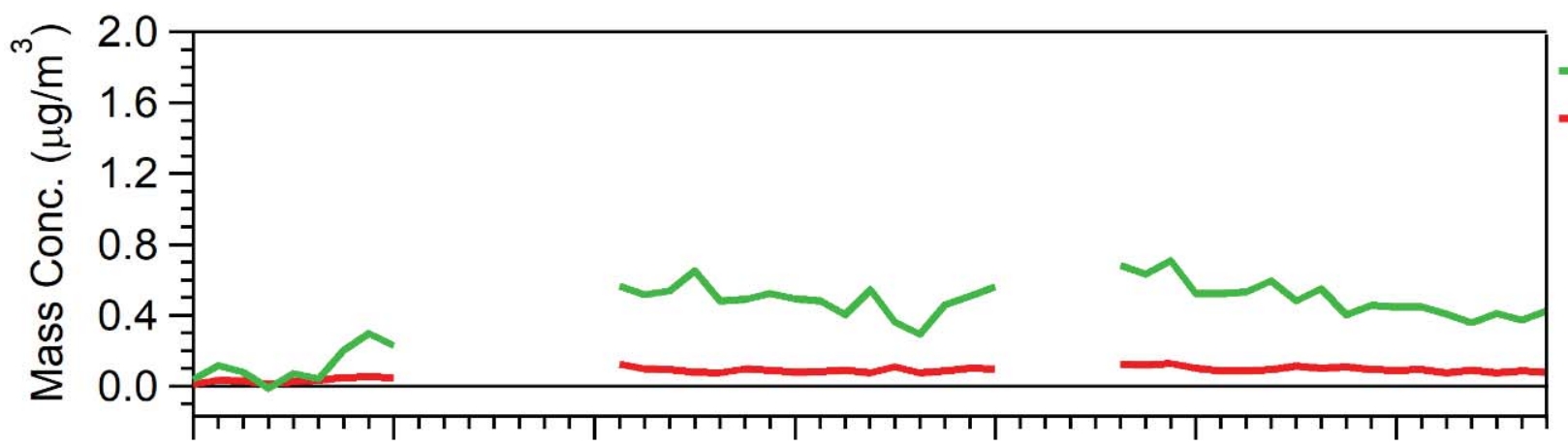

Organics $\mathrm{SO}_{4}$

(b)

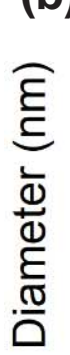
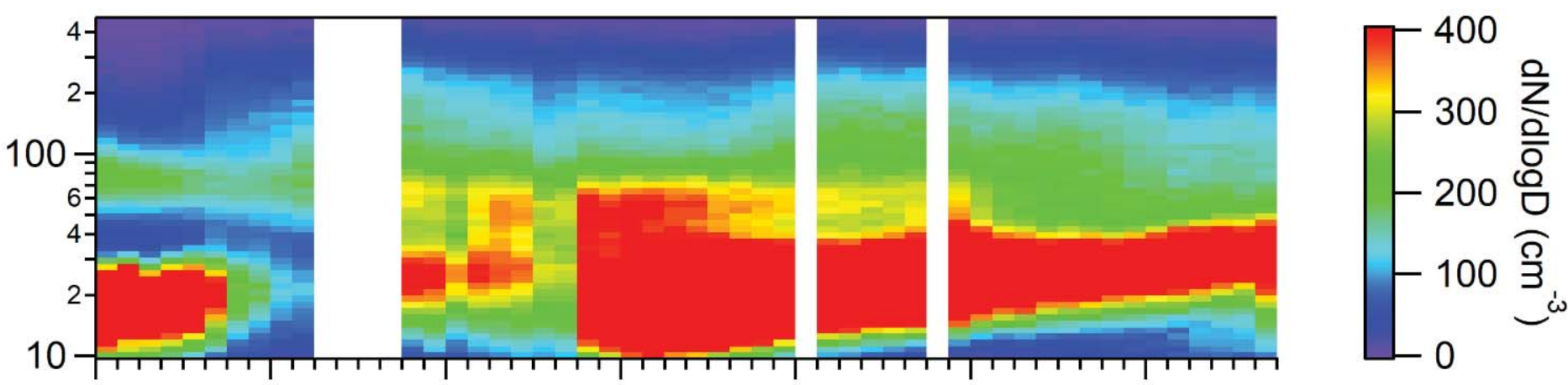
07:00
15:00
23:00
07:00
15:00
23:00
07:00
2015-07-28 2015-07-29
2015-07-30
Date (UTC)

(c)

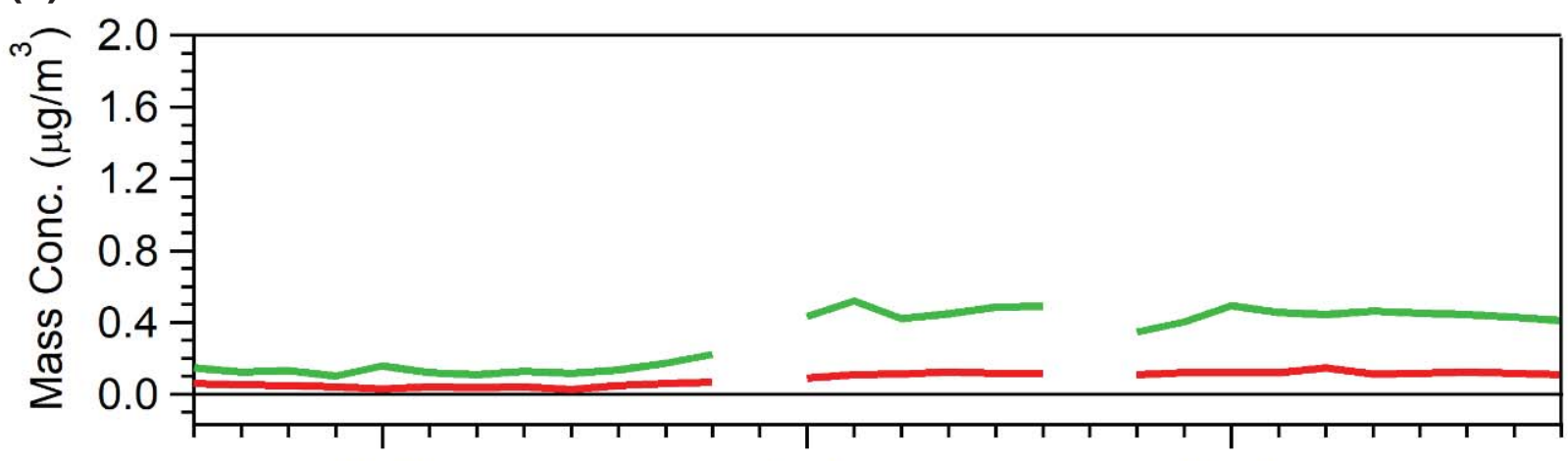

Organics $\mathrm{SO}_{4}$

(d)

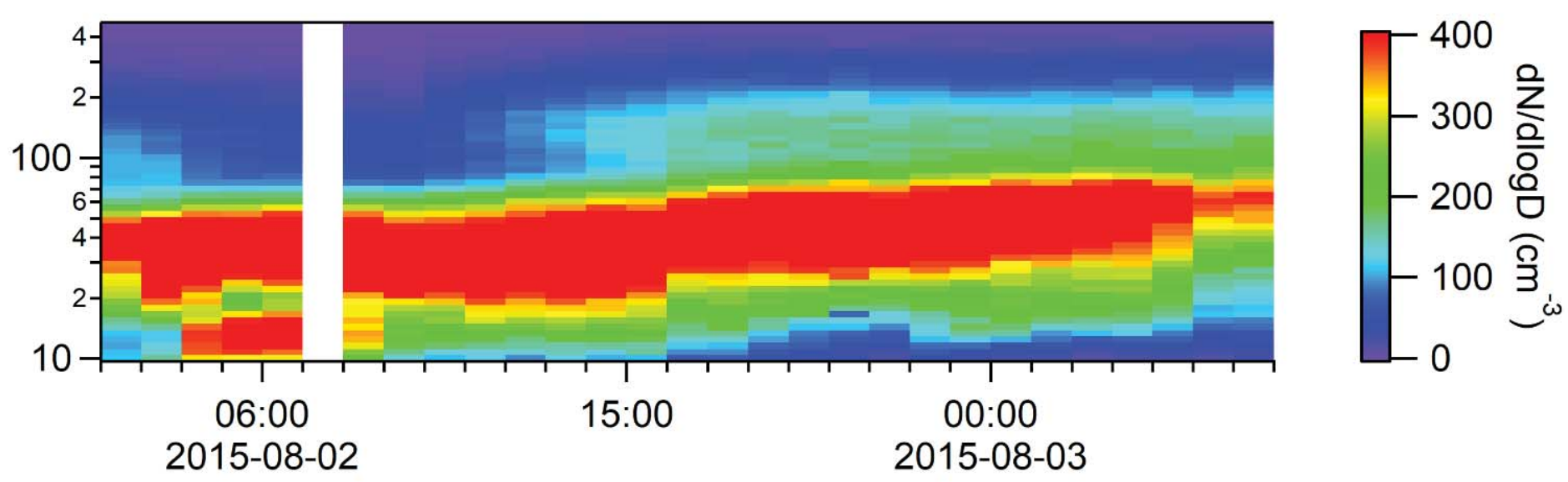

Date (UTC)

Figure S12. Aerosol mass spectrometry measurements of aerosol composition taken at the PEARL RidgeLab near Eureka showing only the organic and sulphate $\left(\mathrm{SO}_{4}\right)$ composition for GE3 (a) and GE6 (c) and the corresponding SMPS data for GE3 (b) and GE6 (d). The sizes are mobility diameters measured by an SMPS, which are equal to the physical diameters under the assumption that the particles were spherical and contained no voids. 
(a)
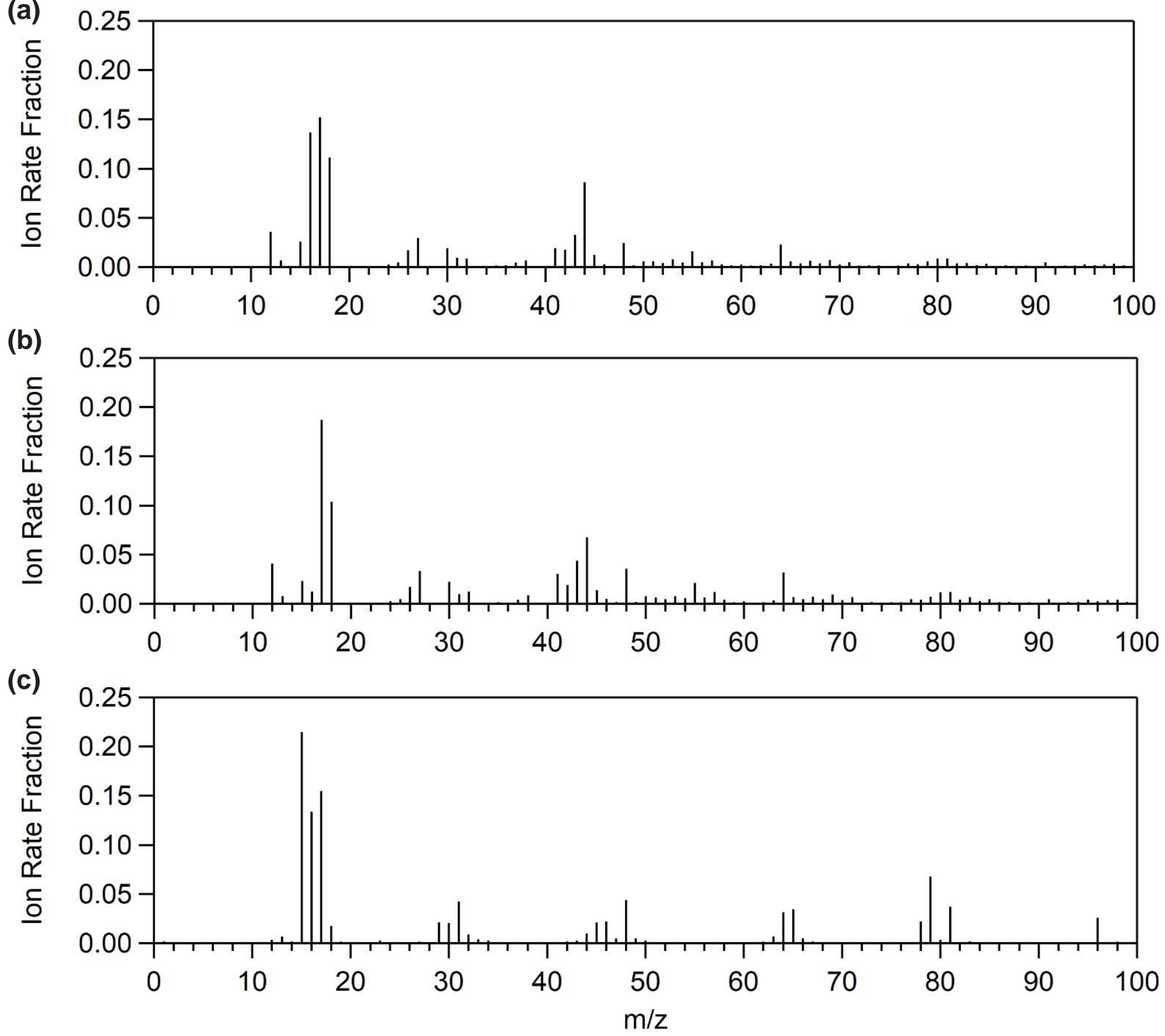

Figure S13. AMS average ambient aerosol mass spectrum of GE 3 (a) and GE 6 (b) compared with the mass spectrum of MSA (c). The Ion Rate Fraction is the normalized Ion Rate (in $\mathrm{Hz}$ ). 


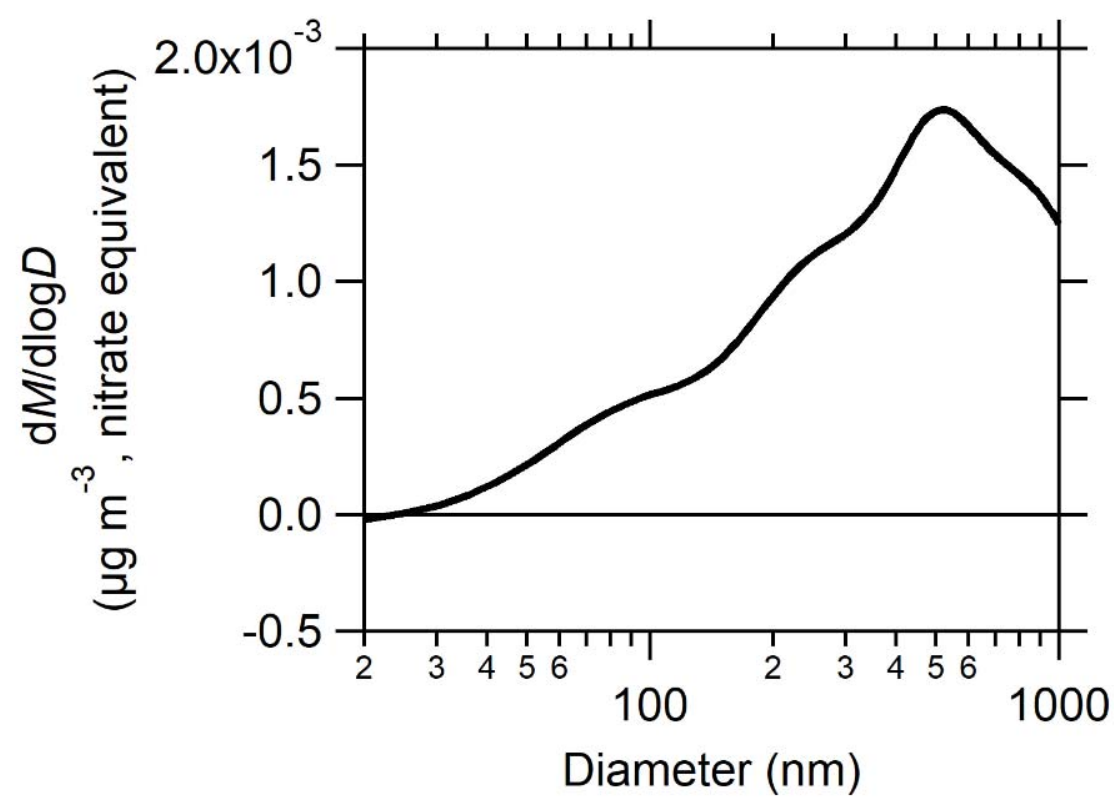

Figure S14. Size distribution at m/z 79 for GE 6 . 
(a)

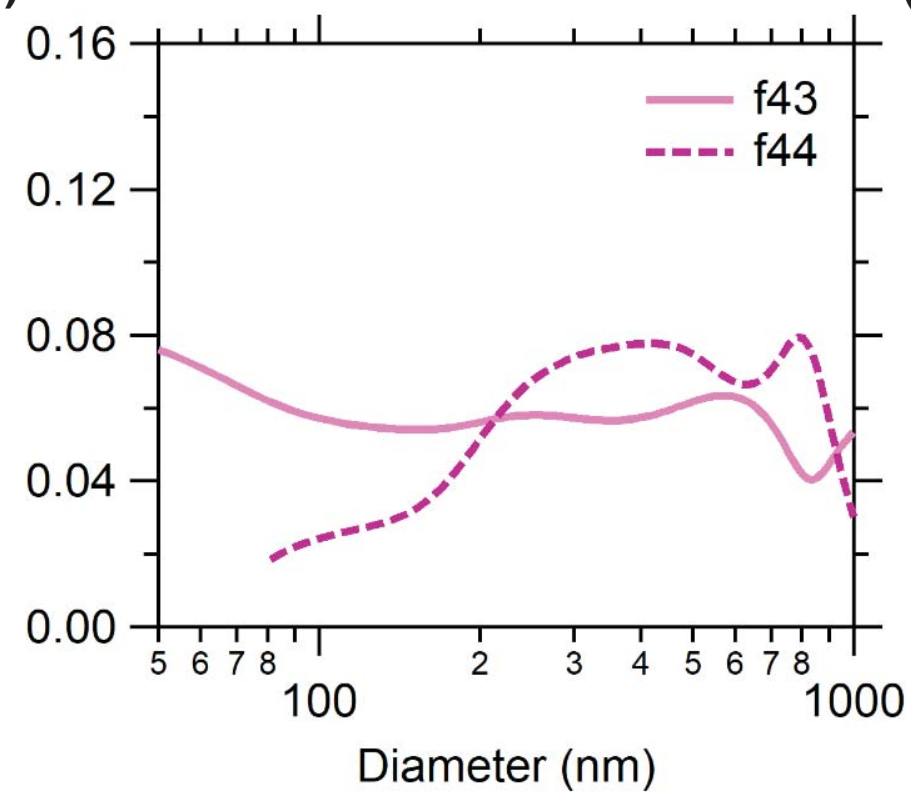

(b)

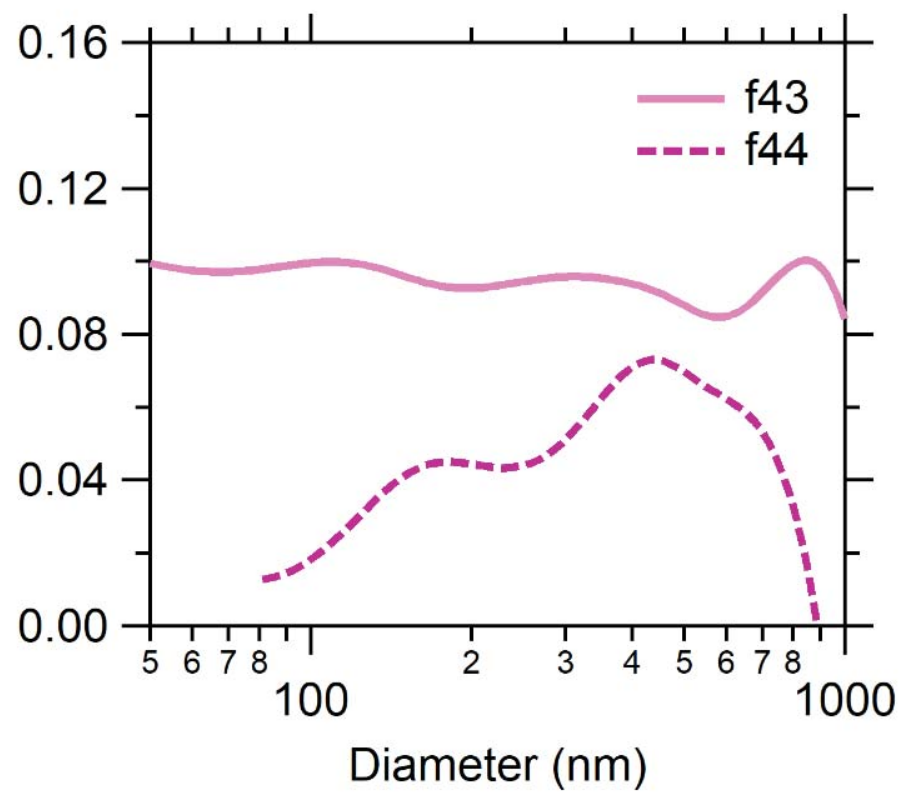

Figure S15. Organic aerosol fraction measured at $\mathrm{m} / \mathrm{z} 43$ and m/z 44 during GE 3 (a) and GE 6 (b) near Eureka. 

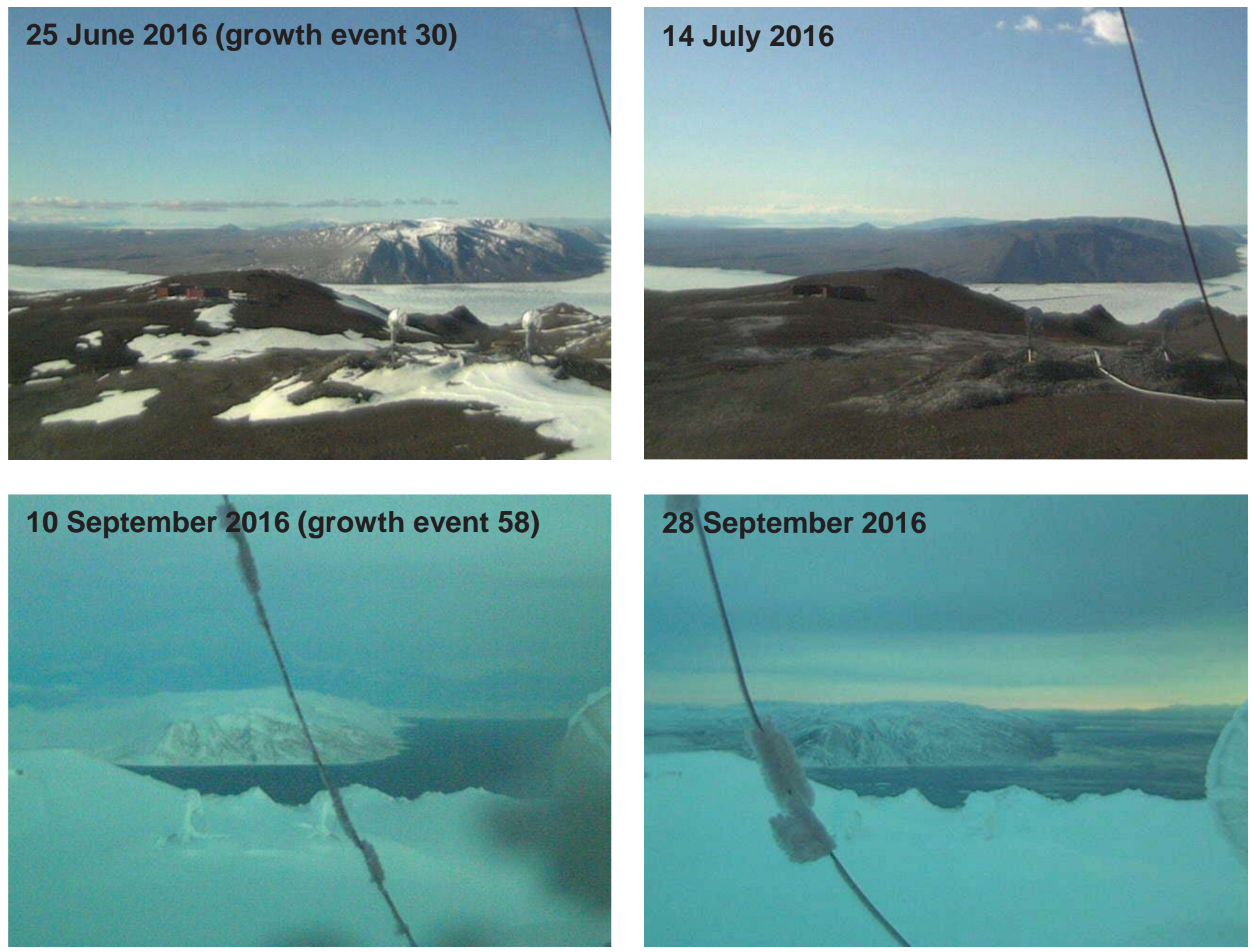

Figure S16. Photos from the PEARL RidgeLab, at $610 \mathrm{~m}$ above sea level. The images correspond to: the first observed growth event for 2016 (25 June), the first time open water is observed (14 July), the last observed growth event for 2016 (10 September), and the last image available for the year (28 September) due to poor visibility related to meteorological conditions as well as polar sunset. 


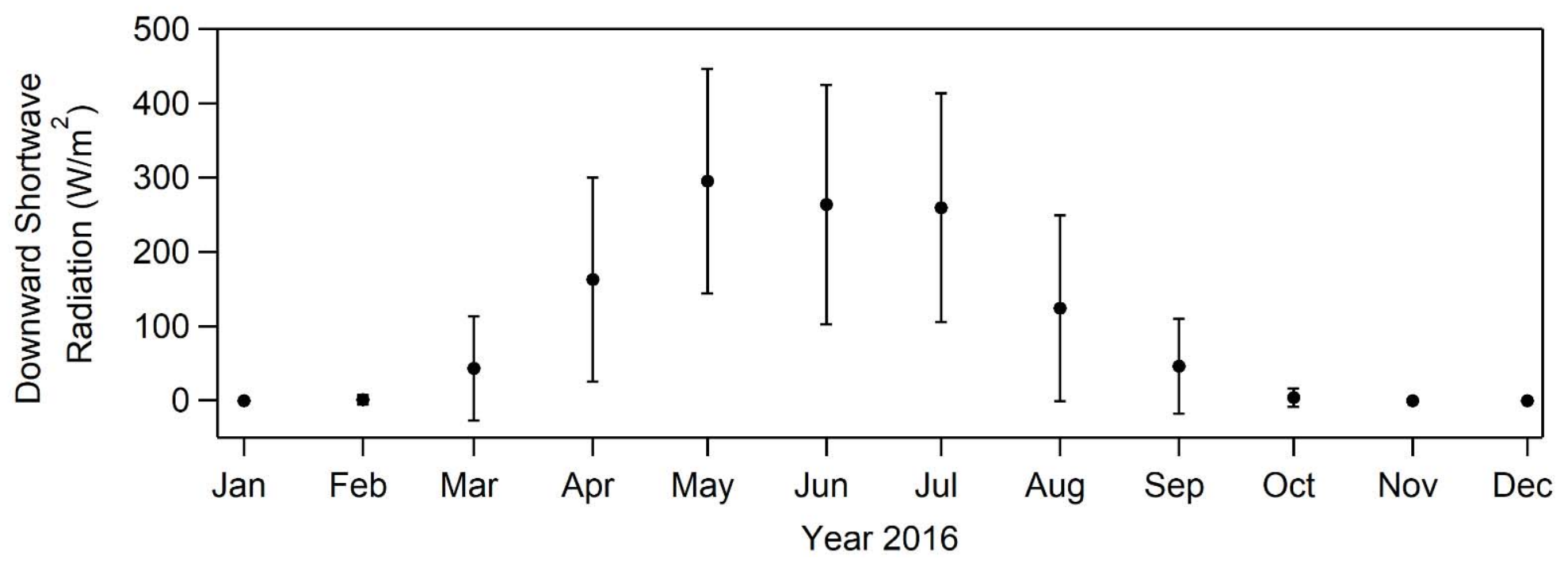

Figure S17. Average by month of the downwelling shortwave radiation for the year 2016 at Eureka, as measured at the SAFIRE facility at $85 \mathrm{~m}$ above sea level. The standard deviation of the one-minute average fluxes for each month is indicated along with the average. 